Eastern Illinois University

The Keep

Masters Theses

Student Theses \& Publications

1975

\title{
The Intramolecular Torsional Potential and Dielectric Properties of 2,3-Butanedione
}

Gevert H. Meyer

Eastern Illinois University

This research is a product of the graduate program in Chemistry at Eastern Illinois University. Find out more about the program.

\section{Recommended Citation}

Meyer, Gevert H., "The Intramolecular Torsional Potential and Dielectric Properties of 2,3-Butanedione" (1975). Masters Theses. 3498. https://thekeep.eiu.edu/theses/3498

This is brought to you for free and open access by the Student Theses \& Publications at The Keep. It has been accepted for inclusion in Masters Theses by an authorized administrator of The Keep. For more information, please contact tabruns@eiu.edu. 
TO: Graduate Degree Candidates who have written formal theses.

SUBJECT: Permission to reproduce theses.

The University Library is receiving a number of requests from other institutions asking permission to reproduce dissertations for inclusion in their library holdings. Although no copyright laws a re involved, we feel that professional courtesy demands that permission be obtained from the author before we allow theses to be copied.

Please sign one of the following statements:

Booth Library of Eastern Illinois University has my permission to lend my thesis to a reputable college or university for the purpose of copying it for inclusion in that institution's library or research holdings.

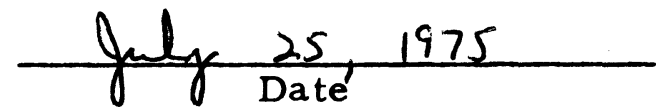

I respectfully request Booth Library of Eastern Illinois University not allow my thesis be reproduced because

pdm 


\section{DIELECTRIC PROPERTIES OF 2,3-BUTANEDIONE (TITLE)}

BY

GEVERT H. MEYER

B. S., Quincy College, 1973

\section{THESIS}

SUBMITTED IN PARTIAL FULFILLMENT OF THE REQUIREMENTS FOR THE DEGREE OF Master of Science

IN THE GRADUATE SCHOOL, EASTERN ILLINOIS UNIVERSITY CHARLESTON, ILLINOIS

\section{5}

YEAR

I HEREBY RECOMMEND THIS THESIS BE ACCEPTED AS FULFILLING THIS PART OF THE GRADUATE DEGREE CITED ABOVE

$\frac{\operatorname{July} 23 \quad 1975}{\text { DATE }}$

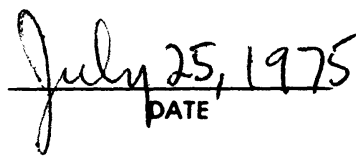


Dipole moment measurements have been carried out on 2,3-butanedione in solution, pure liquid, and the vapor phase. A dipole moment of $1.03 \pm .01$ Debye was observed for dilute solutions of 2,3-butanedione in carbon tetrachloride. Pure liquid samples exhibit an anomalous dipole of $1.56 \pm .01$ Debye. The following results were obtained for vapor phase measurements: $1.04,1.07,1.08,1.11$, and $1.17 \pm .01$ Debye at $310.15,350.15,370.15,431.70$ and $472.10 \pm .02^{\circ} \mathrm{K}$ respectively.

The acetyl torsional potential was characterized from the observed temperature dependence of dipole moment. This torsional mode was described by a two-parameter potential function: $V(\theta)=\frac{V 1}{2}(1-\cos \theta)+$ $\frac{V 2}{2}(1-\cos 2 \emptyset)$ where $\emptyset$ is the acetyl torsional angle. The temperature dependence of the dipole moment was analyzed using statistical thermodynamic methods to determine the internal rotation potential parameters $V_{1}$ and $V_{2}$. A numerical least squares fit of the data yields $V 1=2890 \pm 30 \mathrm{~cm}^{-1}(8.26 \pm .09 \mathrm{Kcal}$ or $34.6 \pm .3 \mathrm{KJ})$ and $0.0<V 2<20 \mathrm{~cm}^{-1}$.

A two parameter potential function has been employed for the first time to characterize the temperature dependence of the dipole moment. The results of this study indicates that in contrast to glyoxal, the cis isomer of 2,3-butanedione is unstable, and accounts for the failure of other experimental methods to observe this isomer. 


\section{ACKNOWLEDGMENTS}

I wish to express my sincere appreciation to Dr. Giles Henderson for suggesting this problem and for providing guidance and assistance throughout the investigation.

I would also like to thank Dr. J. W. Ellis for his assistance in glassblowing, Mr. Charles Tucker for his help from the stockroom, and Mrs. Roger Haberer for typing this manuscript.

Grateful acknowledgment is also extended to Eastern Illinois University Research Committee for their support. 
TABLE OF CONTENTS

Page

ACKNOWLEDGMENTS . . . . . . . . . . . . . . . . . i i

LIST OF FIGURES • • • • • • • • • • • • • • • • • • • • v

INTRODUCTION •. . . . . . . . . . . . . . . . . . 1

EXPERIMENTAL . . . . . . . . . . . . . . . . 7

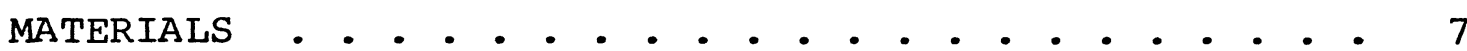

PURIFICATION OF MATERIALS . . . . . . . . . . . . 7

EQUIPMENT AND APPARATUS • • • • • • • • • • • • • 9

RESULTS • • • . • • • • • • • • • • • • • 24

PURE LIQUID MEASUREMENTS • • • • • • • • • • . 24

SOLUTION MEASUREMENTS • • • • • • • • • • • • 28

VAPOR-PHASE MEASUREMENTS • . • . • • • • • • . 39

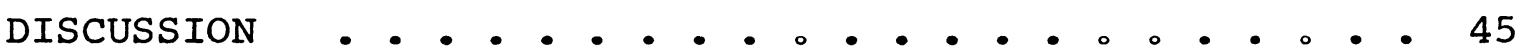

COMPARISON OF RESULTS WITH OTHER

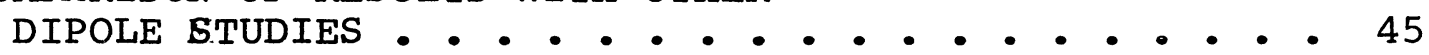

DIPOLE MOMENT AND INTRAMOLECULAR

ROTATION •. •. •. . . . . . . . . . . . . 48

TORSIONAL POTENTIAL MODEL • • • • • • • • • . . 52

DETERMINATION OF POTENTIAL PARAMETERS • • • • • • • 59

POTENTIAL PARAMETERS FROM OTHER METHODS . • . • • 63

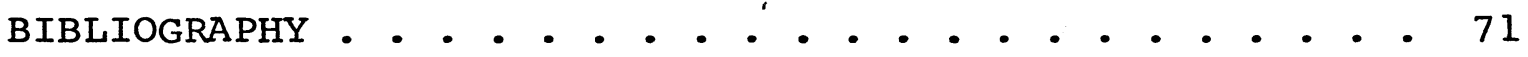

APPENDIXES

1. SPECTRAL DATA AND VAPOR PHASE

CHROMATOGRAPHS . . . . . . . . . . . 73 
2. FORTRAN COMPUTER PROGRAMS . . . . . . . . . 84

3. THEORETICAL RELATIONSHIPS OF

DIELECTRIC CONSTANT, POLARIZATION,

AND DIPOLE MOMENTS • • • • • • • • • • • 96

4. BOND MOMENTS AND MOLECULAR DIPOLE

MOMENT • • • • • • • • • • • • • • • • 104 
LIST OF FIGURES

Figure

Page

1. Comparison of Bloom and Sutton's

Data with Zahn's Data . . . . . . . . . 4

2. Dielectric Cell Used for Pure Liquid and Solution Measurements . . . . . . . . 11

3. Dielectric Cell Used for Gas Phase Measurements . . . . . . . . . 15

4. Vacuum Line Used in Vapor Phase Diagram • • • • • • • • • • • • • • 17

5. Corrections for Changes in Background . . . . 21

6. Calibration Curve for the Dielectric Standards Used in the Pure Liquid Measurements . . . . . . . . . 25

7. Calibration Curve forr the Dielectric Standards Used in the Solution Measurements . . . . . . . . . . . . 30

8. Plot of the Dielectric Constant Versus

Mole Fraction for Solutions of 2,3Butanedione in Carbon Tetrachloride . • . . 35

9. Plot of the Density Versus Mole Fraction for Solutions of 2,3Butanedione in Carbon Tetrachloride . . . 37

10. Calibration Curve for Nitrogen Gas at $310.15^{\circ} \mathrm{K}$. . . . . . . . . . . . 40

11. Comparison of Results with other Dipole Studies . . . . . . . . . . . . 47

12. Angular Dependence of 'Three OneParameter Potential Functions . . . . . . 55

13. Regression Contours for $R=0.05$, $0.03,0.02$, and 0.015

14. Limiting Potential Energy Curves for Internal Rotation in 2,3-Butanedione Compared with Glyoxal 


\section{INTRODUCTION}

In general, it should be expected that 1,2-dicarbonyl compounds may exist as both cis and trans isomers. In these compounds, both the cis and trans isomers would be stabilized by p-orbital overlap and pi bonding between the adjacent $\mathrm{sp}^{2}$ hybridized carbonyl carbon atoms.

The cis isomer of glyoxal, $\mathrm{H}-\mathrm{C}(=0)-\mathrm{C}(=0) \mathrm{H}$, the simplest 1,2-dicarbonyl compound has recently been experimentally observed. It was first detected in 1970 by Currie and Ramsey ${ }^{l}$ with the appearance of a vibrational band at $4875 \mathrm{~A}^{\circ}$ in the uv-emission spectra. It was determined from their studies that the cis isomer lies $1125 \pm 100 \mathrm{~cm}^{-1}$ above the ground vibrational level of the trans isomer. In 1972, further evidence for the cis isomer was obtained from microwave studies made by Durig, Tong, and $\mathrm{Li}^{2}$ when they observed the 1+0 torsional transition frequency of the cis molecule at $114 \pm 8 \mathrm{~cm}^{-1}$ which compares with a predicted value of $107 \mathrm{~cm}^{-1}$ for the molecule in the cis form. The next simplest 1,2-dicarbonyl compound is 2,3-butanedione, $\mathrm{CH}_{3}-\mathrm{C}(=0)-\mathrm{C}(=0) \mathrm{CH}_{3}$. The existence of 2,3-butanedione in two isomeric forms would also be expected but previous experimental work suggests that it exists only in the trans form. Durig, Hannum, and Brown ${ }^{3}$ systematically examined the infrared spectrum of 
2,3-butanedione in the solid, liquid, and gas phases. They observed an absorption feature at $52 \mathrm{~cm}^{-1}$ which they have assigned to the acetyl torsion mode (Fately and co-workers earlier reported a value at $\left.48 \mathrm{~cm}^{-1}\right)^{4}$, but no evidence was found for the existence of the cis isomer. In 1973, vapor phase electron diffraction studies by Hagen and Hedberg 5 were carried out on 2,3-butanedione. From their studies, they also concluded that 2,3-butanedione exists only in the trans configuration. They calculated the potential barrier to intramolecular rotation to be $11.4 \mathrm{Kcal} / \mathrm{mole}\left(3989 \mathrm{~cm}^{-1}\right.$ ) using the harmonic oscillator approximation. The diffraction data enabled them to estimate the frequency of the torsional mode about the $C-C$ bond to be $53 \mathrm{~cm}^{-1}$, which is in good agreement with previously reported infrared observations.

Information about intramolecular rotation about the C-C bond in 1,2-dicarbonyl compounds can also be obtained from the temperature dependence of the dipole moment. In molecules where there are two rotatable dipoles on adjacent carbon atoms, the possibility exists for one dipole to rotate about the $\mathrm{C}-\mathrm{C}$ bond into the trans position and cancel or nearly cancel the other dipole, or it could rotate into the cis position in which case the resultant of the two dipoles would act in the same direction and give a maximum dipole moment. No temperature dependence of the dipole moment will be observed for cases where free rotation of the dipoles is present and 
all positions around the $\mathrm{C}-\mathrm{C}$ bond are equally probable. In cases where the trans isomer is of lower energy than the cis isomer, i.e. rotation is hindered by a potential barrier, then thermal effects will be observed in the dipole moment measurements. As the temperature of the sample increases, the population of the cis isomer becomes statistically more favored. Therefore an increase in temperature results in a higher boltzman population of polar molecules and an increase in the observed dipole moment.

Dipole moment measurements of 2,3-butanedione have been carried out on two previous occasions; Zahn 6 in 1932, and Bloom and sutton ${ }^{7}$ in 1941. The results of their measurements are shown in Figure (1) and it can be seen that a serious discrepancy exists between their sets of data. It should be pointed out that in both cases the dipole moment measurements showed a temperature dependence. Although Zahn's data appears to be qualitatively correct, no mention was made as to how his measurements were obtained. Furthermore, no attempt was made to fit his data to any type of potential function. Bloom and sutton did try fitting their data to one parameter linear, cosine, and parabolic potential functions. However, a one parameter potential fails to take into account the possibility of the existence of both cis and trans isomers. A better model would have been a two parameter potential function describing both cis and trans forms. However, without 
Figure 1

A Comparison of Bloom and Sutton's Data with Zahn's Data 


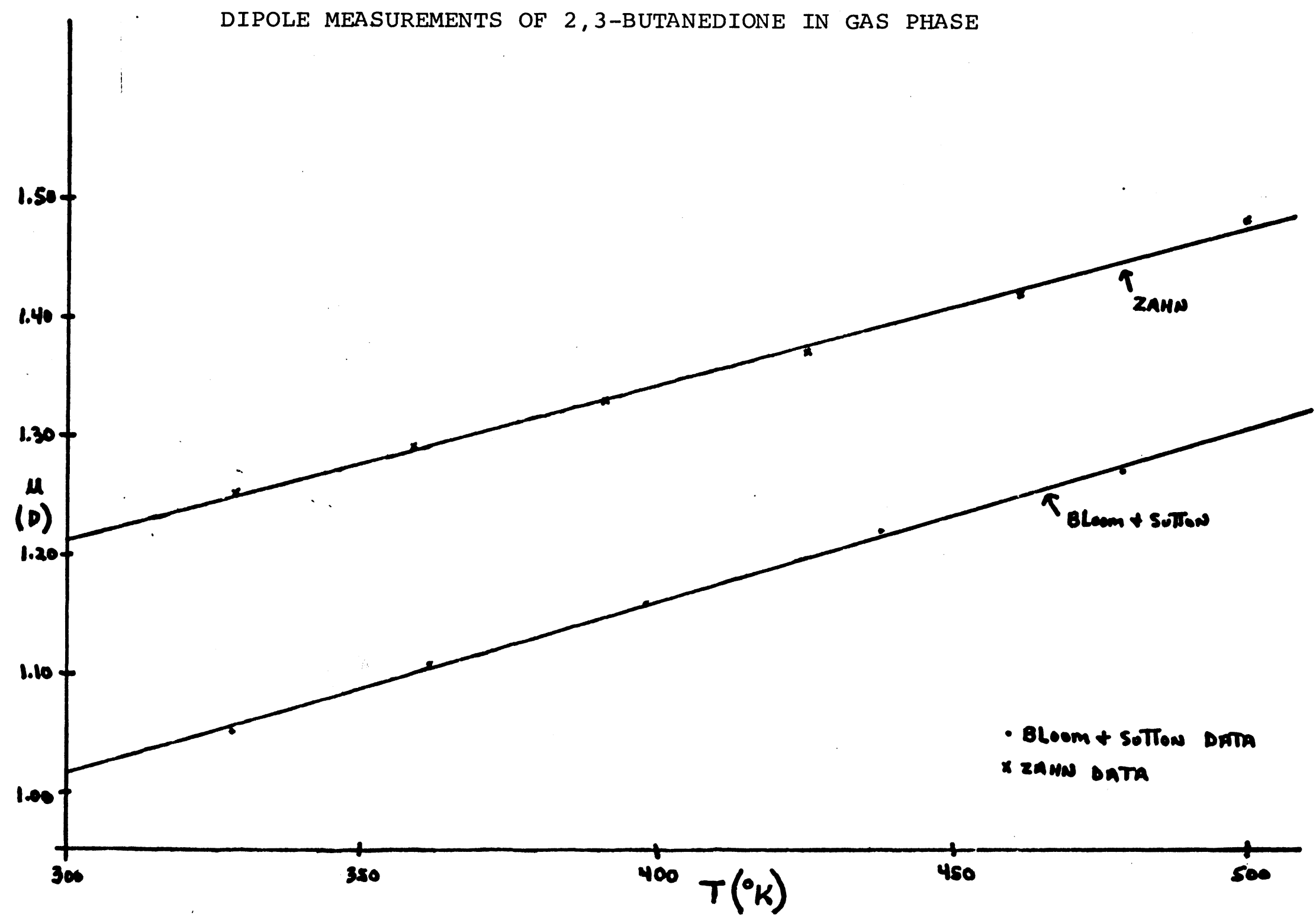


modern day computers, fitting a two parameter potential function to the temperature dependence of the dipole moment was infeasible.

The present dipole moment study of 2,3-butanedione was undertaken to resolve the discrepancy that exists between Bloom and Sutton's dipole moment data and Zahn's data. Moreover, computer techniques will be employed to analyze the dipole moment data to obtain a more accurate description of the torsional potential. The question as to the stability of the cis isomer of 2,3-butanedione can then be answered. 
EXPERIMENTAL

\section{Materials}

For the pure liquid and solution measurements, a series of materials of known dielectric constants were chosen for calibration standards. The physical properties for these standards are given in Table 1.

Purification of Materials

2,3-Butanedione: 2,3-butanedione was fractionally distilled twice with the middle fraction of the second distillate being used for measurements. The purity was confirmed from NMR spectra and vapor phase chromatograms. (See Appendix 1)

Benzene: 11 Reagent grade benzene (500ml) was boiled for ten hours with $40 \mathrm{~g}$ anhydrous aluminum chloride then distilled. The distillate was washed several times with water and finally refluxed for two hours with acetic acid and mercuric oxide. After washing with water and sodium hydroxide it was refluxed over sodium metal for 12 hours and then fractionally distilled over sodium. Cyclohexane: 11 Cyclohexane was passed through an alumina column $3 \mathrm{~cm}$. in diameter and $30 \mathrm{~cm}$. long and fractionally distilled through a $30 \mathrm{~cm}$. fractionating column after refluxing over $\mathrm{P}_{4} \mathrm{O}_{10}$ for twelve hours. Only the middle fraction was saved. 
Table 1

All Values Given for $25^{\circ} \mathrm{C}$

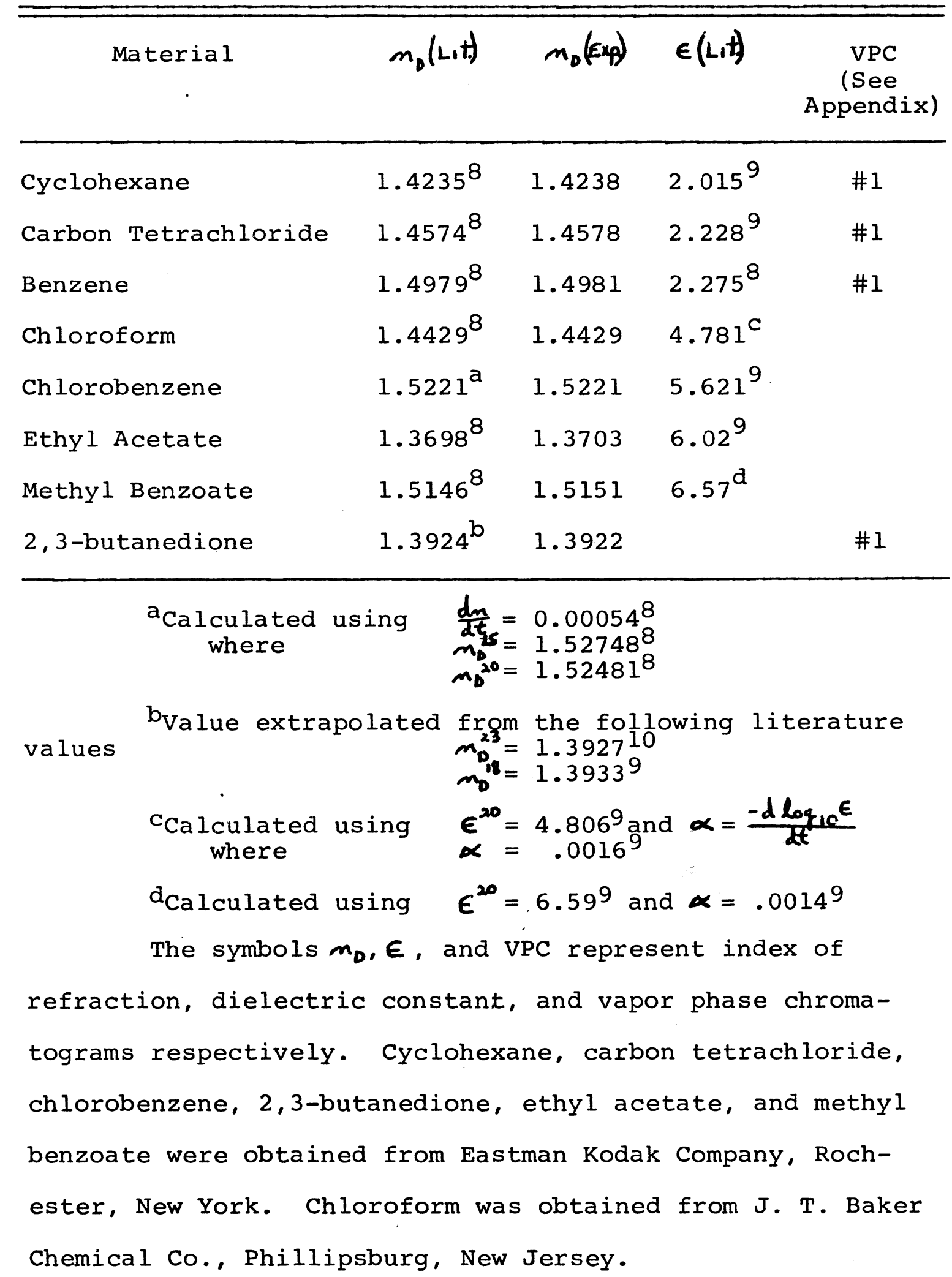


Carbon Tetrachloride: Carbon tetrachloride was prepared by fractionally distilling twice. The middle portion of the distillation was kept for use.

Chloroform: 11 Chloroform was washed three times with concentrated sulfuric acid, neutralized with $\mathrm{NaHCO}_{3}$ and washed with water. After drying over $\mathrm{MgSO}_{4}$, it was fractionally distilled under a nitrogen atmosphere, saving only the middle fraction.

Chlorobenzene: Reagent grade chlorobenzene was used without further purification.

The benzene, cyclohexane, carbon tetrachloride, chloroform, and chlorobenzene were stored in the dark over type $4 \mathrm{~A}$ molecular sieve, grade 514 that had been freshly prepared by heating at $320^{\circ} \mathrm{C}$ for three hours in a thermostated tube furnace.

\section{Equipment and Apparatus}

The indices of refraction were measured with a Bausch and Lomb Abbe refractometer. The vapor phase chromatograms (VPC) were obtained using a Perkin Elmer Model 154-L, equipped with a thermal conductivity detector, and a $10 \mathrm{ft}$. column of $15 \%$ SE-30 stationary phase, with helium carrier gas at a flow rate of $78 \mathrm{ml} /$ minute. Weight measurements were made using a Sartorius single pan balance. Density measurements for the pure liquid were made using a stopper type pycnometer. Density measurements of solutions were made using $25-\mathrm{ml}$. volumetric flasks. Infrared (ir) spectra were made using 
a Perkin-Elmer 337 Infrared Spectrophotometer. Nuclear magnetic resonance spectra were obtained using a Varian T-60 NMR spectrophotometer system. Mass spectral data was obtained with a Dupont 21-490 Mass Spectrometer. A dielectrometer constructed in this laboratory was used to obtain dielectric measurements by the heterodyne beat method from which dipole moments were calculated.a

The dielectric cell (See Figure 2), model 2TN20LV, used for pure liquid and solution measurements was obtained from Balsbaugh Laboratories, Duxbury, Massachusetts and was modified for this experiment. $b$ Dielectric measurements of up to $\boldsymbol{\epsilon}=3.0$ are permitted by this cell.

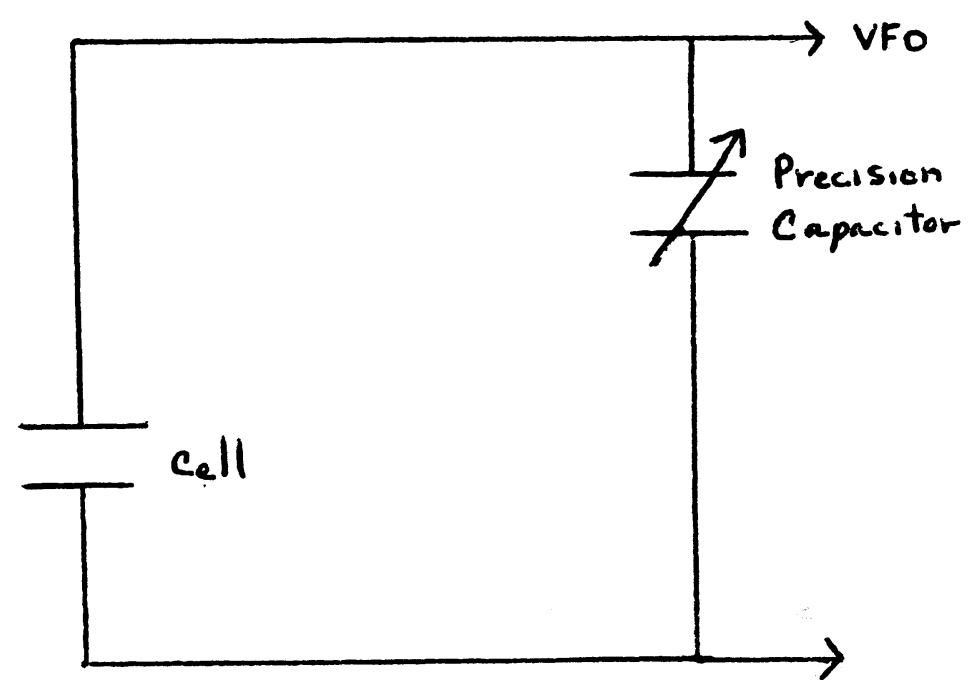

A 110 pf mica capacitor was used in series with the cell to permit measurements of dielectric constants up to $\epsilon=15.0$. This was necessary for pure liquid measurements.

a The instrument was constructed by Mr. James Belcher $\mathrm{b}_{\mathrm{Cell}}$ modified by Dr. J. W. Ellis 
Figure 2

Dielectric Cell Used for Pure Liquid and Solution Measurements 


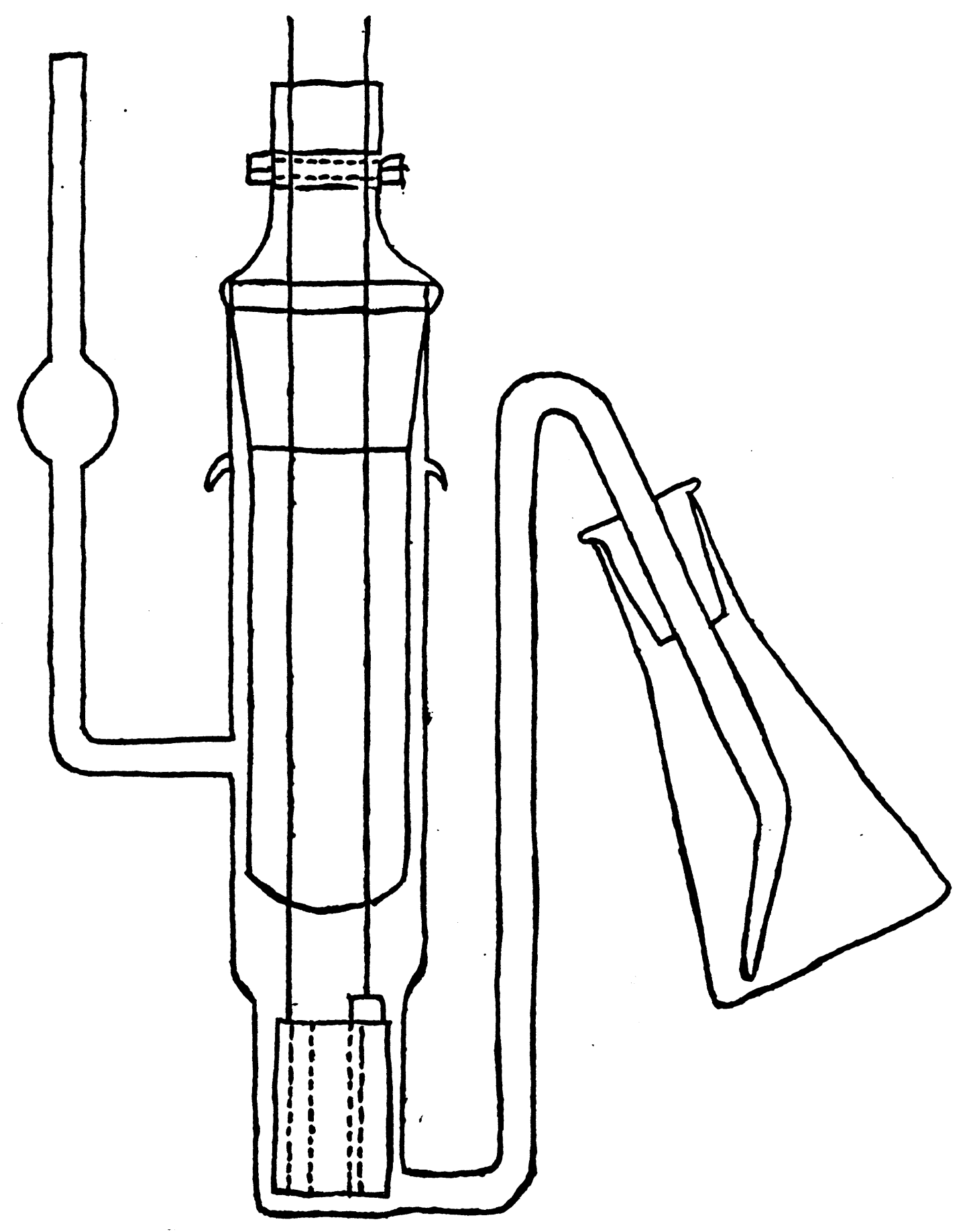




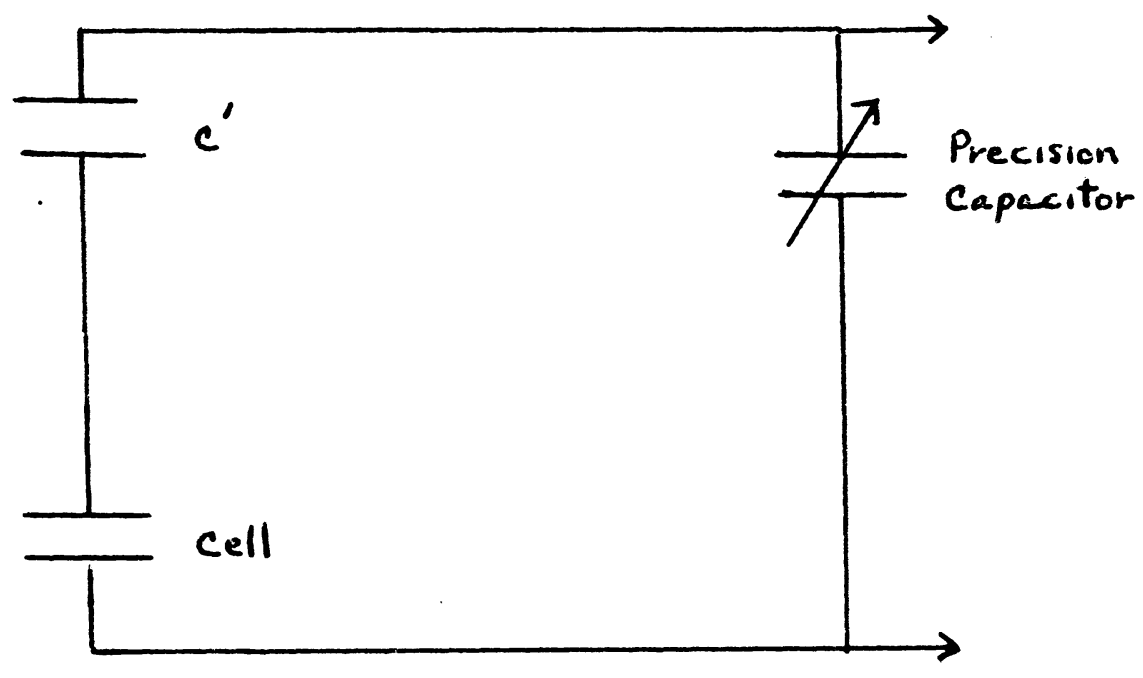

where $c^{\prime}=110 \mathrm{pf}$

The tuning mechanism of a war surplus frequency meter (Model No. BC221N) was used to measure changes in capacitance. Although the BC22 IN provides a high precision vernier dial mechanism, an accurate calibration technique is needed since the measured changes in capacitance are nonlinear with respect to dial readings. The samples were introduced into the cell by means of a vacuum and were removed by pressurizing the cell with nitrogen gas. Fifteen to twenty milliliters of liquid are required by the cell for each measurement.

The null points for measurements were obtained under a nitrogen gas atmosphere. Before taking any measurements the instrument was turned on for several days to minimize frequency shifts due to thermal effects. After 
introducing each sample into the thermostated cell, five minutes were allowed for temperature equilibrium to be reached. The sample temperature was held constant within $\pm 0.03^{\circ} \mathrm{C}$, with a Magni Whirl constant temperature bath. The calibration of the instrument was achieved by measuring a series of standard materials of known dielectric constant as a function of dial settings. The parameters for a polynomial calibration function were then obtained for this data using a nonlinear least squares fit. (See Appendix 2)

A custom built dielectric cell and vacuum line (See Figure 3 and 4) were used for vapor phase measurements. The cell was placed in an oilbath that was surrounded by vermiculite type insulation. The temperature of the oilbath was controlled by a YSI Model 71A Thermistemp Temperature Controller. A variac voltage regulator was used to maintain the temperature as constant as possible. It was found that each experimental temperature had an optimum voltage at which temperature regulation was best achieved. A Forma Temperature Junior Bath and Circulator was used to regulate the temperature of the 2,3-butanedione sample.

Vapor phase measurements required measuring very small changes in dielectric constants, i.e. $\Delta \epsilon=1.0 \times 10^{-4}$. Therefore, the capacitance of the instrument had to be altered to meet the requirements as shown in the following diagram. 
Figure 3

The Dielectric Cell Used for Gas Phase Measurements 


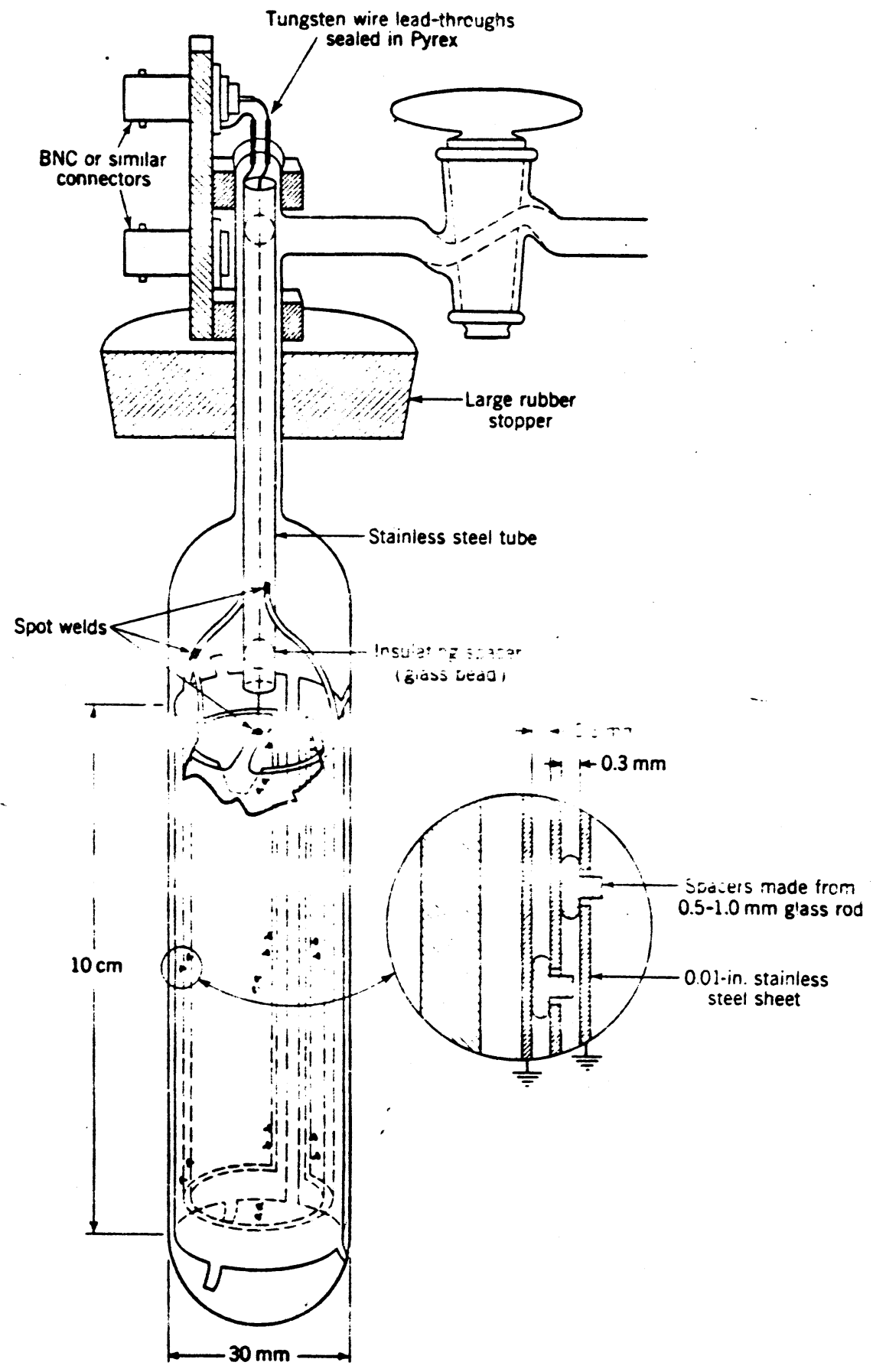


Figure 4

Vacuum Line Used in Vapor Phase Diagram 


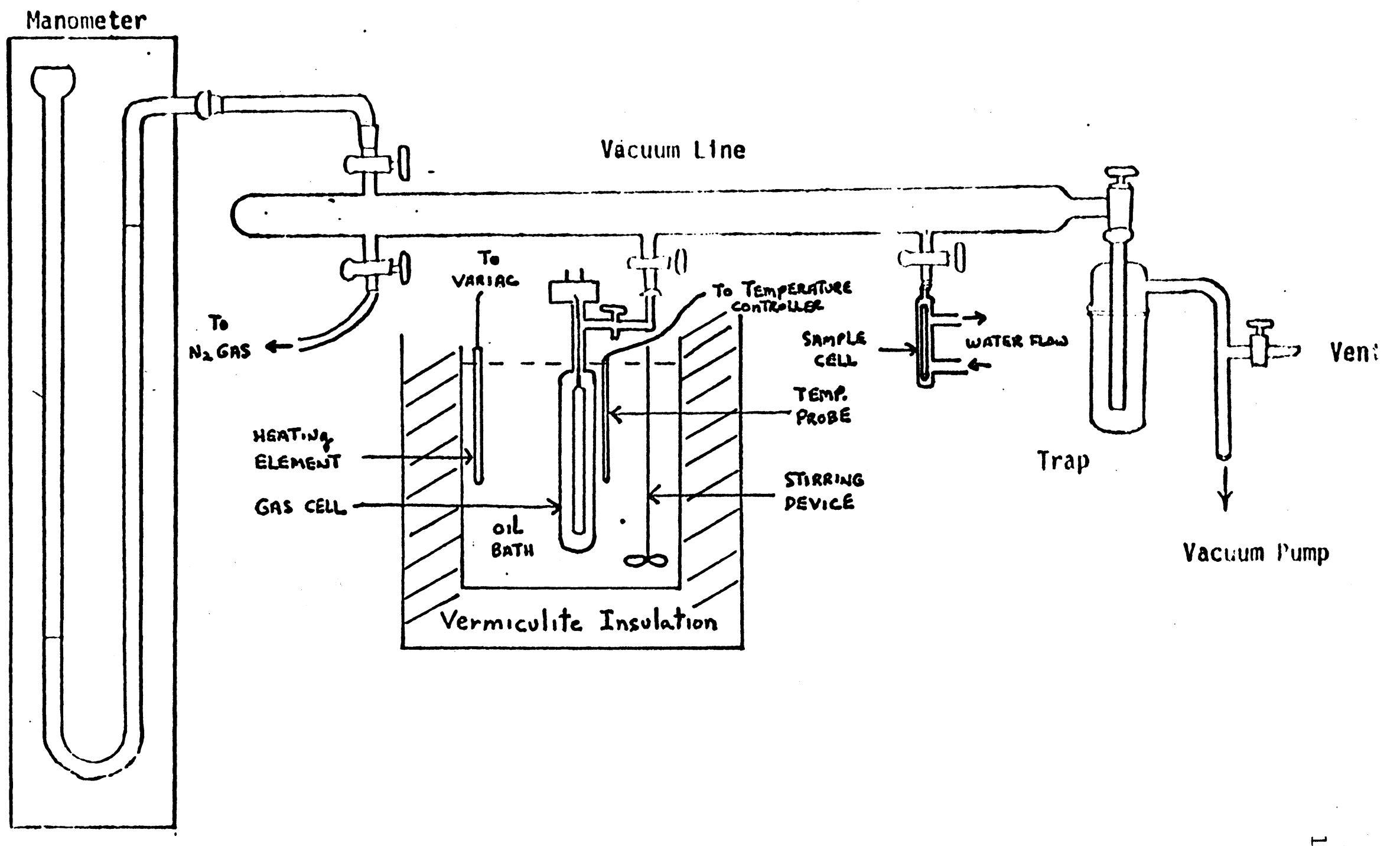




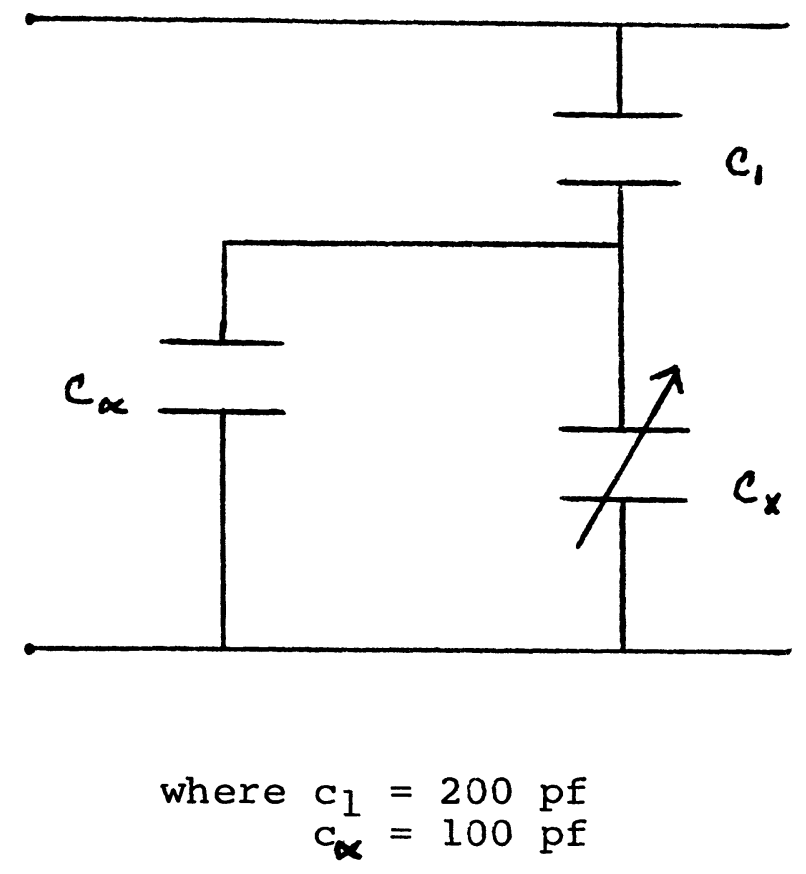

The variable frequency oscillator (VFO) was set at $1.30 \mathrm{MHz}$. The first overtone band was used to zero beat with the fixed crystal oscillator at $2.60 \mathrm{MHz}$ for these measurements.

The experimental procedure used for vapor phase measurements was as follows. The dielectric cell, filled with nitrogen gas, was heated to the desired temperature. The heating element power was adjusted until the temperature fluctuation of the oilbath was less than $\pm 0.02^{\circ} \mathrm{K}$ for the lower temperatures and $\pm 0.06^{\circ} \mathrm{K}$ at the higher temperatures. The nitrogen gas in the cell was then evacuated and a dial reading recorded for the null point of the evacuated cell. A Lab Chron 1400 timer was also started at this point and all readings thereafter were recorded as a function of time. 
Background fluctuations were observed by evacuating the cell after each gas measurement and taking a dial reading. Background corrections were then made with respect to the time zero dial setting, i.e. a positive deviation in the background was substracted from the observed dial setting. (See Figure 5) When taking gas measurements, at least ten minutes were allowed for temperature equilibrium. Dial readings were then taken approximately every forty to fifty seconds for about four minutes. Any change in background could then be observed. An average of all the dial settings was taken and the midpoint of the time readings recorded.

The temperature of the 2,3-butanedione was maintained at $15.1 \pm 0.1^{\circ} \mathrm{C}$ throughout the course of all gas measurements. Nitrogen gas was used as a dielectric calibration standard having a dielectric constant equal to $1.0005472^{9}$ at $20^{\circ} \mathrm{C}$ and 760 torr pressure. During each set of measurements a calibration curve was obtained by taking nitrogen gas dial readings at pressures of $200,250,300$, 350, and 400 torr. The parameters for the calibration curve were obtained by using a nonlinear least squares fit. (See Appendix 2)

A determination of the dipole moment at each temperature required some 75 nitrogen calibration null point observations and approximately 45 sample null point observations over a period of approximately six hours. A total of over 2000 vapor phase measurements were made over 
Figure 5

Corrections for Changes in Background Are Shown 


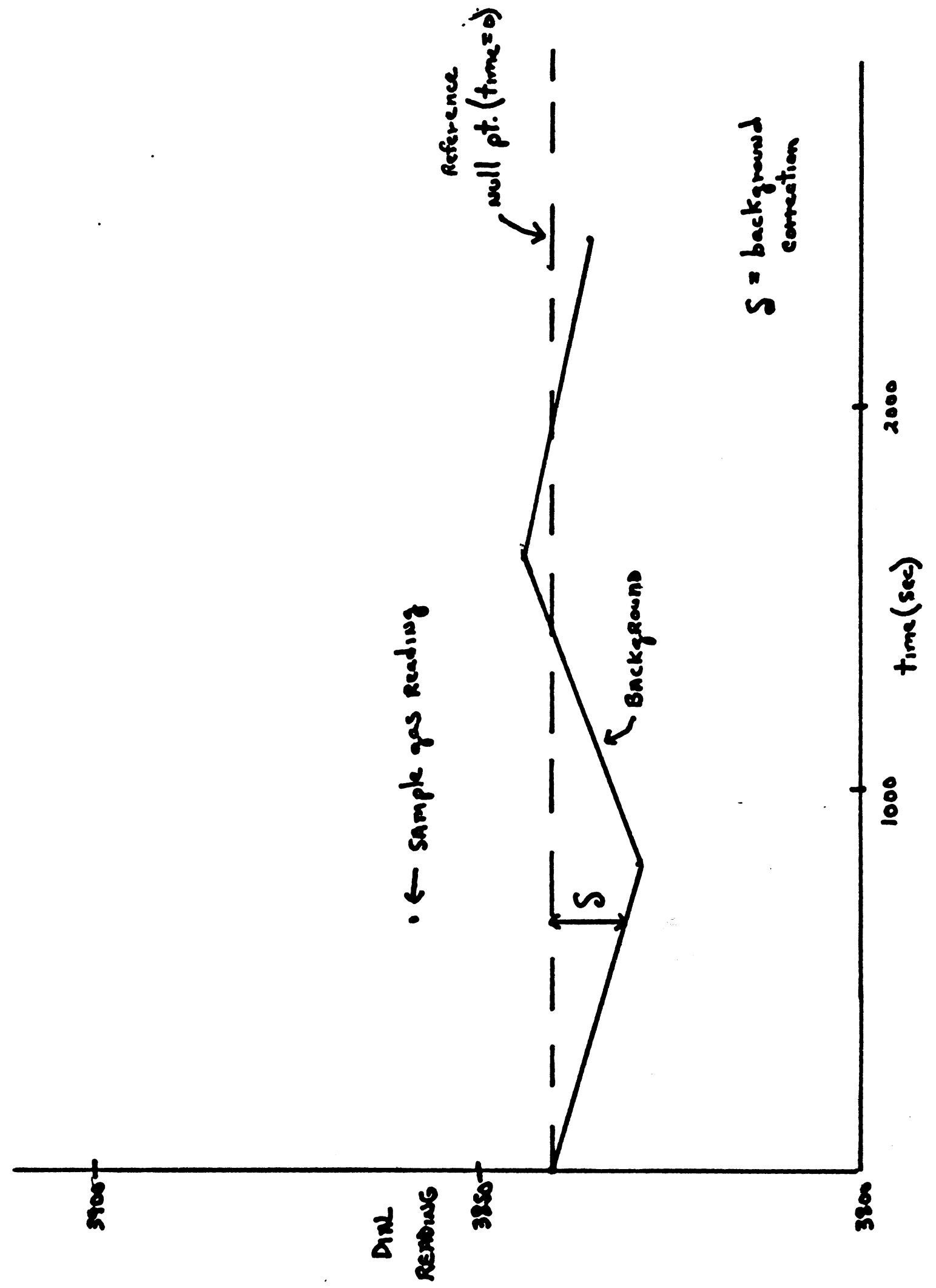


the accessible temperature range. 


\section{RESULTS}

Pure Liquid Measurements

The coefficients of the polynomial calibration function were determined from the data in Table II by a non-linear least squares fit. (See Appendix 2)

Table II

Measurements at $25^{\circ} \mathrm{C}$

\begin{tabular}{lcccc}
\hline \multicolumn{1}{c}{ Material } & $N$ & $\bar{S}$ & $\sigma$ & $\epsilon$ (Lit.) \\
\hline Cyclohexane & 4 & 588.48 & .046 & $2.015^{9}$ \\
Carbon Tetrachloride & 4 & 643.98 & .538 & $2.228^{9}$ \\
2,3 -butanedione & 4 & 1376.2 & .524 & \\
Chloroform & 4 & 1406.3 & 1.304 & 4.781 \\
Chlorobenzene & 4 & 1719.3 & 1.055 & $5.621^{9}$ \\
Ethyl Acetate & 4 & 1872.6 & 2.311 & $6.02^{9}$ \\
Methyl Benzoate & 4 & 2173.1 & 1.926 & 6.57 \\
\hline
\end{tabular}

Where $N$ represents number of trials, $\bar{\delta}$ is the average value for dial setting, $\sigma$ is the standard deviation for dial setting, and $\epsilon$ is the dielectric constant.

A second ordered polynomial was found to fit the calibration curve. (See Figure 6) The equation for the 


\section{Figure 6}

The Calibration Curve for the Dielectric Standards Used in the Pure Liquid Measurements 


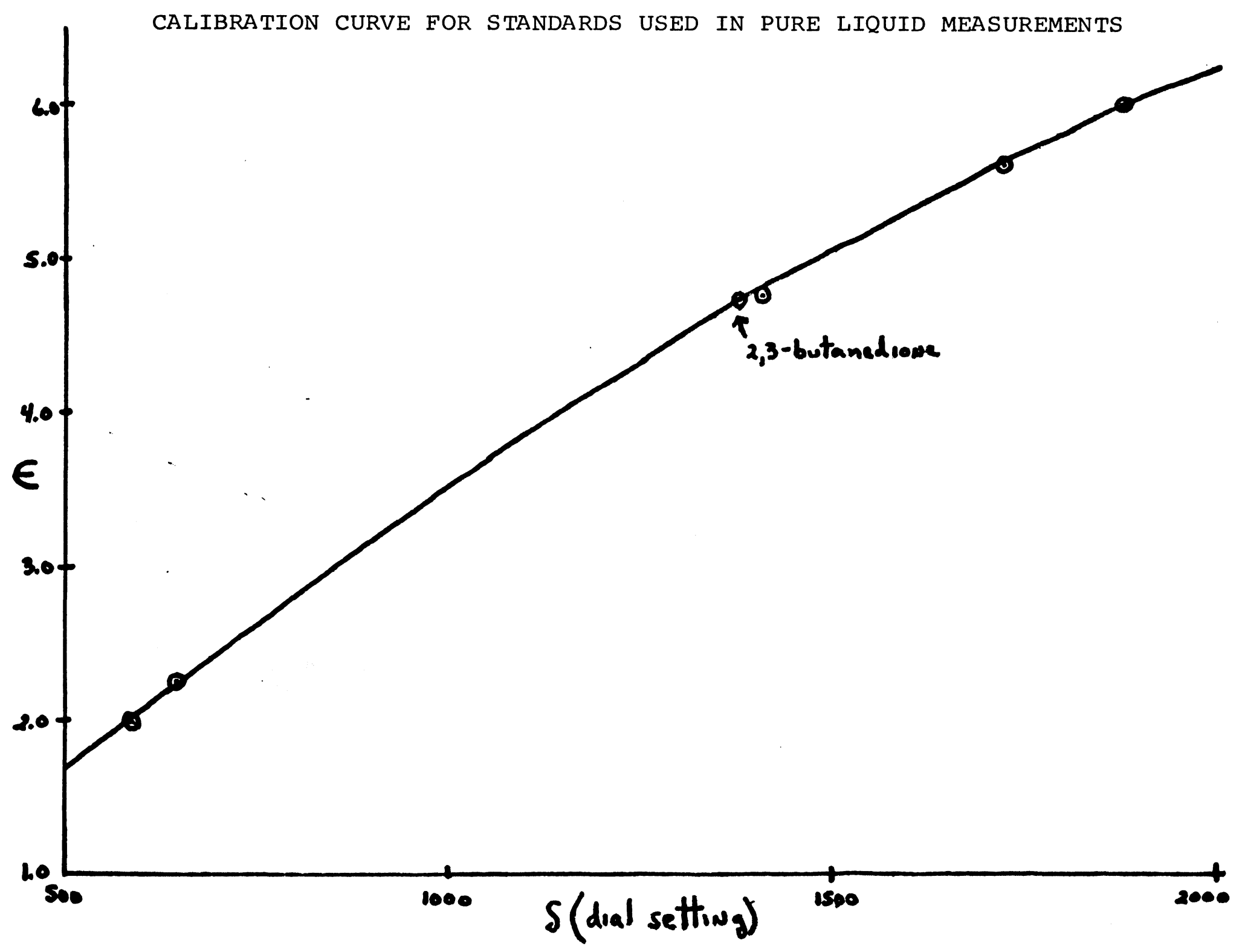


calibration curve is

$$
\epsilon=A_{0}+A_{1} \delta+A_{2} \delta^{2}
$$

Where $A_{O}=-0.5604519$

$$
\begin{aligned}
& A_{1}=0.4770201 \times 10^{-2} \\
& A_{2}=-0.6815654 \times 10^{-6}
\end{aligned}
$$

The dielectric constant of pure 2,3-butanedione was calculated from the observed dial setting and the above calibration equation as $\quad \in=4.713 \pm .002$. The density of 2,3-butanedione was determined as $.981 \mathrm{~g} / \mathrm{ml}$ at $25^{\circ} \mathrm{C}$.

The molar polarization $\left(P_{m}\right)$, distortion polarization $\left(P_{d}\right)$, orientation polarization $\left(P_{u}\right)$, and dipole moment were then calculated from the Onsager equation. (See Appendix 3)

$$
\begin{aligned}
& \mathrm{P}_{\mathrm{m}}=\frac{\epsilon-1}{\epsilon+2}\left(\frac{M}{P}\right) \\
& \mathrm{R}_{\mathrm{m}}=\mathrm{P}_{\mathrm{E}}=\frac{m^{2}-1}{m^{2}+2}\left(\frac{M}{\rho}\right) \\
& \mathrm{P}_{\mathrm{u}}=\mathrm{P}_{\mathrm{m}}-\mathrm{P}_{\mathrm{d}}=\frac{4 \pi \mathrm{N} \mu^{2}}{9 k T} \\
& \text { Where } \quad \in=\text { dielectric constant } \\
& \quad \rho=\text { density }
\end{aligned}
$$

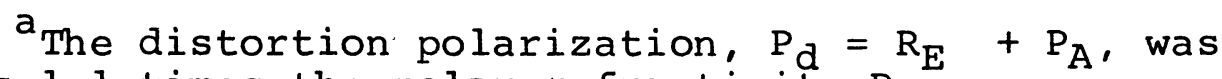
taken as 1.1 times the molar refractivity $R_{m}$. 


$$
\begin{aligned}
& M=\text { molecular weight } \\
& M=\text { index of refraction } \\
& N=\text { Avagadro's number } \\
& k=\text { Boltzmann constant } \\
& T=\text { temperature } \\
& \mu=\text { dipole moment }
\end{aligned}
$$

The results for liquid 2,3 -butanedione at $25^{\circ} \mathrm{C}$ :

$$
\begin{aligned}
& \epsilon \quad=4.713 \pm 0.002 \\
& \mathrm{P}_{\mathrm{m}}=48.522 \pm 0.038 \\
& \mathrm{P}_{\mathrm{d}}=22.988 \pm 0.004 \\
& \mathrm{P}_{\mathrm{u}}=25.534 \pm 0.035 \\
& \mu
\end{aligned}
$$

The dipole moment for 2,3-butanedione in the liquid phase was found to be much higher than expected. (See Figure 1 - Bloom and Zahn Graph) Such deviations have been observed in polar liquids and have been attributed to strong dipole-dipole intermolecular interaction. These interactions can be minimized by measuring dipole moments in dilute solutions rather than in the pure liquid state.

\section{Solution Measurements}

Data for the dielectric standards are given in Table III. The coefficients of the polynomial calibration function were determined from this table by a non-linear least squares fit. (See Appendix 2) 
Table III

Measurements at $25^{\circ} \mathrm{C}$

\begin{tabular}{lcccc}
\hline \multicolumn{1}{c}{ Material } & $N$ & $\bar{S}$ & $\sigma \delta$ & $\epsilon($ Lit.) \\
\hline Cyclohexane & 3 & 588.6 & 0.0 & $2.015^{9}$ \\
Carbon Tetrachloride & 3 & 645.33 & .058 & $2.228^{9}$ \\
Benzene & 3 & 655.83 & .058 & $2.275^{8}$ \\
Chloroform & 4 & 1409.8 & 2.56 & 4.781 \\
Chlorobenzene & 4 & 1725.2 & .645 & $5.621^{9}$ \\
\hline
\end{tabular}

$\mathrm{N}$ represents the number of trials, $\bar{S}$ is the average value for dial setting, $\sigma \delta$ is the standard deviation for dial setting, and $\mathcal{E}$ is the dielectric constant.

The coefficients for the calibration function were determined by a non-linear least squares fit. A second ordered polynomial was found to fit the calibration cruve. (See Figure 7)

The equation for the calibration curve is

$$
\epsilon=A_{0}+A_{1} \delta+A_{2} \delta^{2}
$$

Where $\mathrm{A}_{0}=-0.4849983$

$$
\begin{aligned}
& A_{1}=0.4610520 \times 10^{-2} \\
& A_{2}=-0.6208537 \times 10^{-6}
\end{aligned}
$$

The parameters for the polynomial calibration function were then used to determine the dielectric 
Figure 7

The Calibration Curve for the Dielectric Standards Used in the Solution Measurements 
CALIBRATION CURVE OF STANDARDS FOR SOLUTION MEASUREMENTS

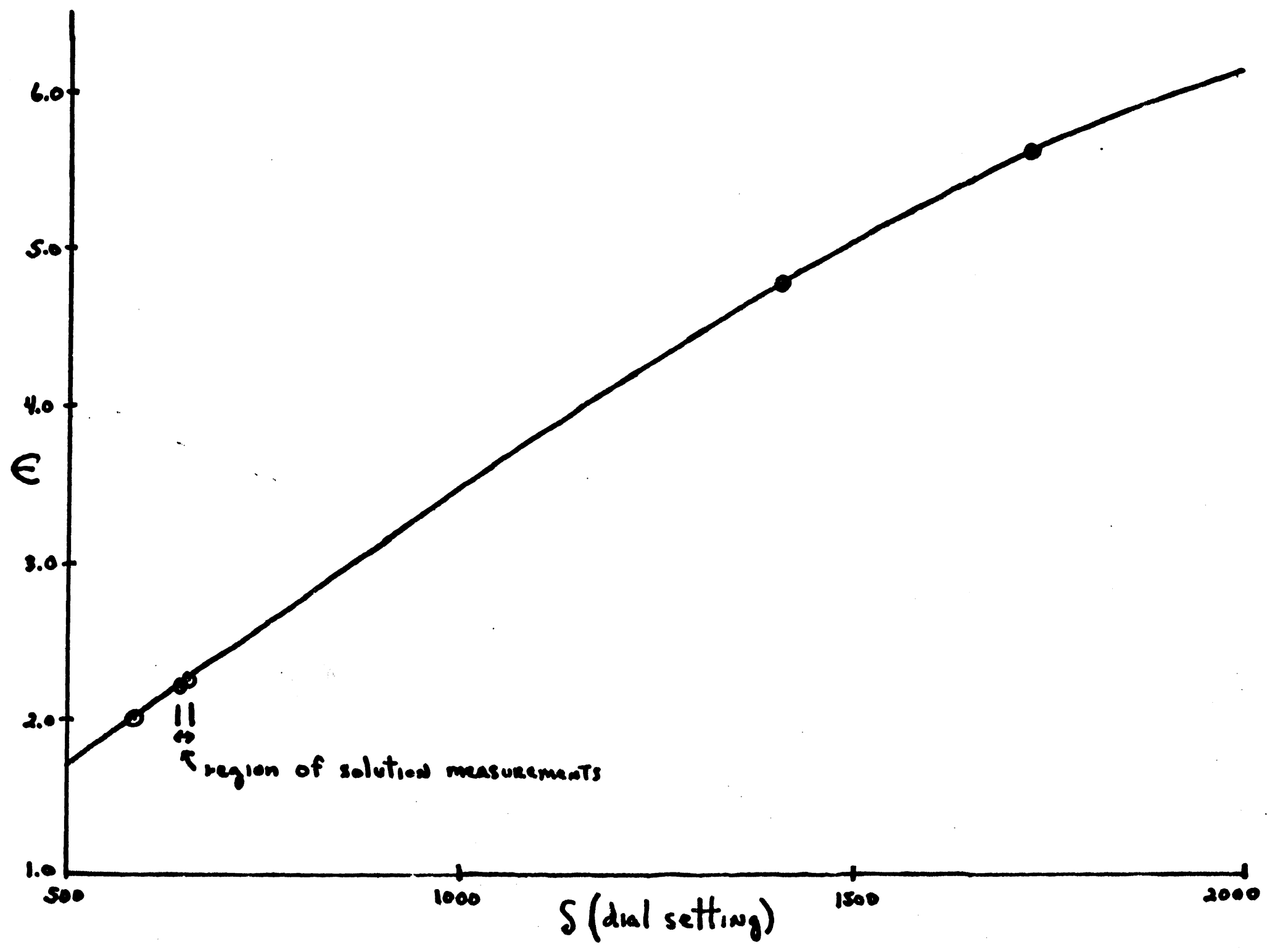

$\stackrel{\omega}{\sim}$ 
constants for dilute solutions of 2,3-butanedione in $\mathrm{CCl}_{4}$. These values are given in Table IV.

Table IV

Measurements at $25^{\circ} \mathrm{C}$

\begin{tabular}{rllll}
\hline \hline & $\bar{x}_{2}$ & $\bar{\delta}$ & $\epsilon$ & $\rho$ \\
\hline Pure CCl 4 & 0.0 & 645.33 & 2.232 & 1.584 \\
Solution \#1 & 0.01564 & 649.3 & 2.247 & 1.580 \\
$\# 2$ & 0.02603 & 652.0 & 2.257 & 1.573 \\
$\# 3$ & 0.03047 & 655.7 & 2.271 & 1.566 \\
$\# 4$ & 0.04569 & 658.4 & 2.281 & 1.558 \\
$\# 5$ & 0.06075 & 662.9 & 2.298 & 1.548 \\
\hline
\end{tabular}

In Table IV, $\in$ represents dielectric constant, $\bar{x}_{2}$ is the mole fraction of solute (2,3-butanedione), $\rho$ represents density, and $\bar{\delta}$ is the average value for the dial settings.

Both dielectric constants and densities of the solutions are expected to be linear with respect to mole fractions. (See Figure 8 and 9)

$$
\begin{aligned}
& \epsilon_{12}=a \bar{x}_{2}+\epsilon_{1} \\
& \rho_{12}=b \bar{x}_{2}+\rho_{1}
\end{aligned}
$$

Where $\epsilon_{12}$ and $p_{12}$ represent dielectric constant and densities of solutions respectively, $\bar{x}_{2}$ represents 
33

mole fraction of solute, and $\epsilon_{1}$ and $\rho_{1}$ represent dielectric constant and density of solvent respectively. The Hedestrand parameters (a) and (b), (See Appendix 3), were obtained from the data in Table IV using a least squares fit. (See Appendix 2) These parameters were then used to evaluate the molar polarization and dipole moment of solute.

$$
P_{2 m}=\frac{3 m_{1} a}{\left(\epsilon_{1}-2\right)^{2} p_{1}}+\frac{\epsilon_{1}-1}{\left(\epsilon_{1}+2\right) p_{1}}\left(m_{2}-\frac{m_{1} b}{p_{1}}\right)
$$

$$
P_{2 d}=\frac{m_{2}^{2}-1}{m_{2}^{2}+2} \frac{m_{2}}{p_{2}}
$$

$$
P_{2 \mu}=P_{2 m}-P_{2 d}=\frac{4 \pi N_{0} \mu^{2}}{9 k T}
$$

Where $M_{1}$ is the molecular weight of solvent (carbon tetrachloride), $\mathrm{M}_{2}$ is the molecular weight of solute (2,3-butanedione), a is the slope of $\epsilon$ versus $\bar{x}_{2}$ graph, $b$ is the slope of $p$ versus $\bar{x}_{2}$ graph, $\dot{n}_{2}$ is the 
index of refraction of 2,3-butanedione, $\rho_{2}$ is the density of 2,3-butanedione, $p_{1}$ is the density of carbon tetrachloride, $\boldsymbol{E}_{1}$ is the dielectric constant of 2,3butanedione, $\mathrm{P}_{2 \mathrm{~m}}$ is the molar polarization of solute, $\mathrm{P}_{2 \mathrm{~d}}$ is distortion polarization of solute, and $\mathrm{P}_{2} \mathrm{u}$ is the orientation polarization of solute where 2,3-butanedione is the solute

Values used in calculation are:

$$
\begin{aligned}
& \mathrm{M}_{1}=153.8 \mathrm{~g} / \mathrm{mole} \\
& \mathrm{M}_{2}=86.09 \mathrm{~g} / \mathrm{mole} \\
& \mathrm{a}=1.099137 \\
& \mathrm{~b}=-0.6269598 \\
& \mathrm{n}=1.3922 \\
& \rho_{2}=.9814 \mathrm{~g} / \mathrm{ml} \\
& \rho_{1}=1.584 \mathrm{~g} / \mathrm{ml} \\
& \epsilon_{1}=2.232
\end{aligned}
$$

The summary of results for $\mathrm{P}_{2 m}, \mathrm{P}_{2 d}, \mathrm{P}_{2 \mathrm{u}}$, and $\mu$ are as follows:

$$
\begin{aligned}
& \mathrm{P}_{2 \mathrm{~m}}=44.86 \mathrm{cc} \\
& \mathrm{P}_{2 \mathrm{~d}}=22.99 \mathrm{cc} \\
& \mathrm{P}_{2 \mathrm{u}}=23.96 \mathrm{cc} \\
& \mu=1.03 \mathrm{D}
\end{aligned}
$$




\section{Figure 8}

Plot of the Dielectric Constant Versus Mole Fraction For Solutions of 2,3-butanedione in Carbon Tetrachloride.

$\odot$ Represent Experimental Values and the Solid

Line Represents the Least Squares Fit of this Data. 


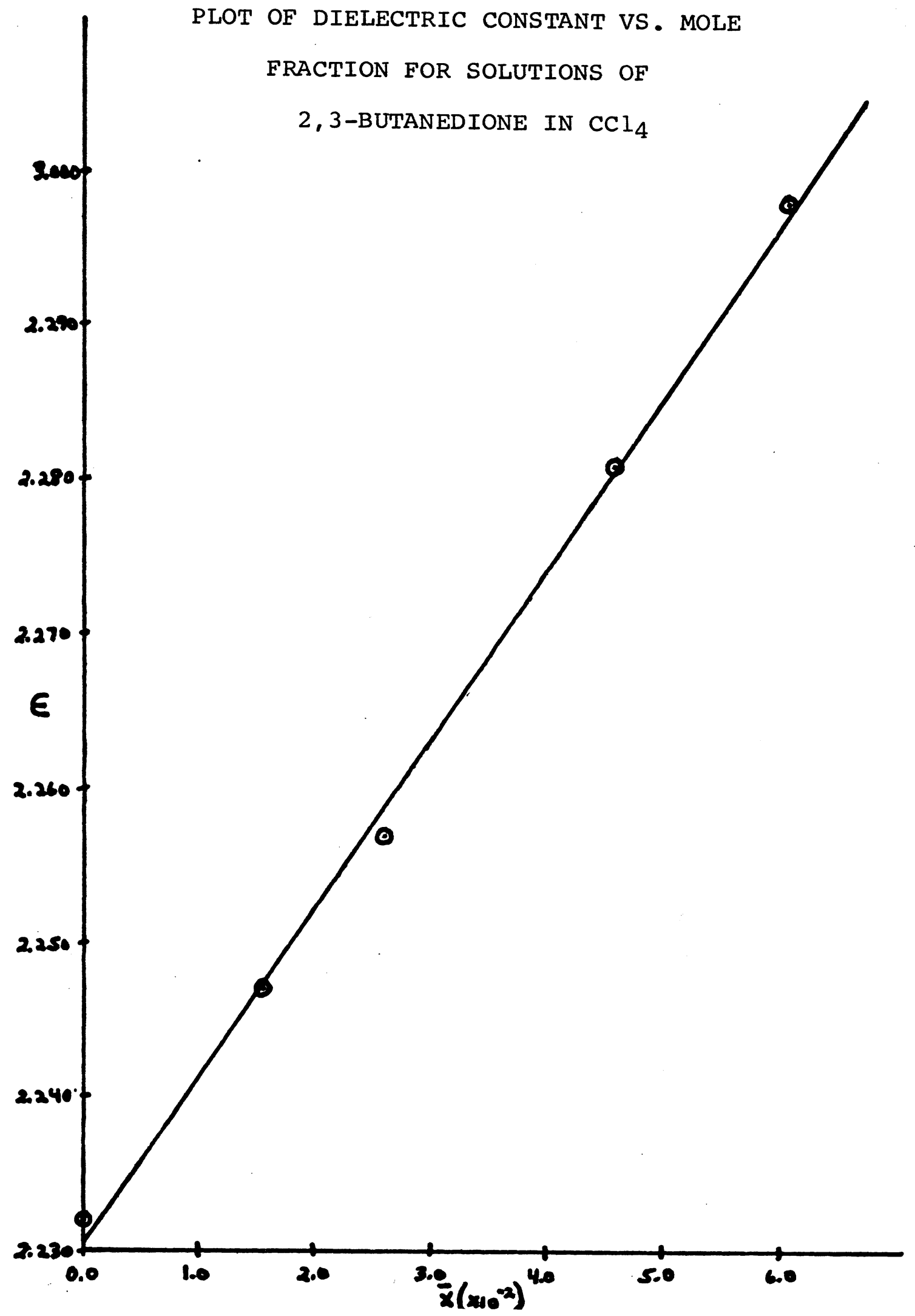


Figure 9

A Plot of the Density Versus Mole Fraction for Solutions of 2,3-butanedione in Carbon Tetrachloride. The Dots

Represent Experimental Data Values. The Solid

Line Represents the Best Least Squares

Fit for the Data. 

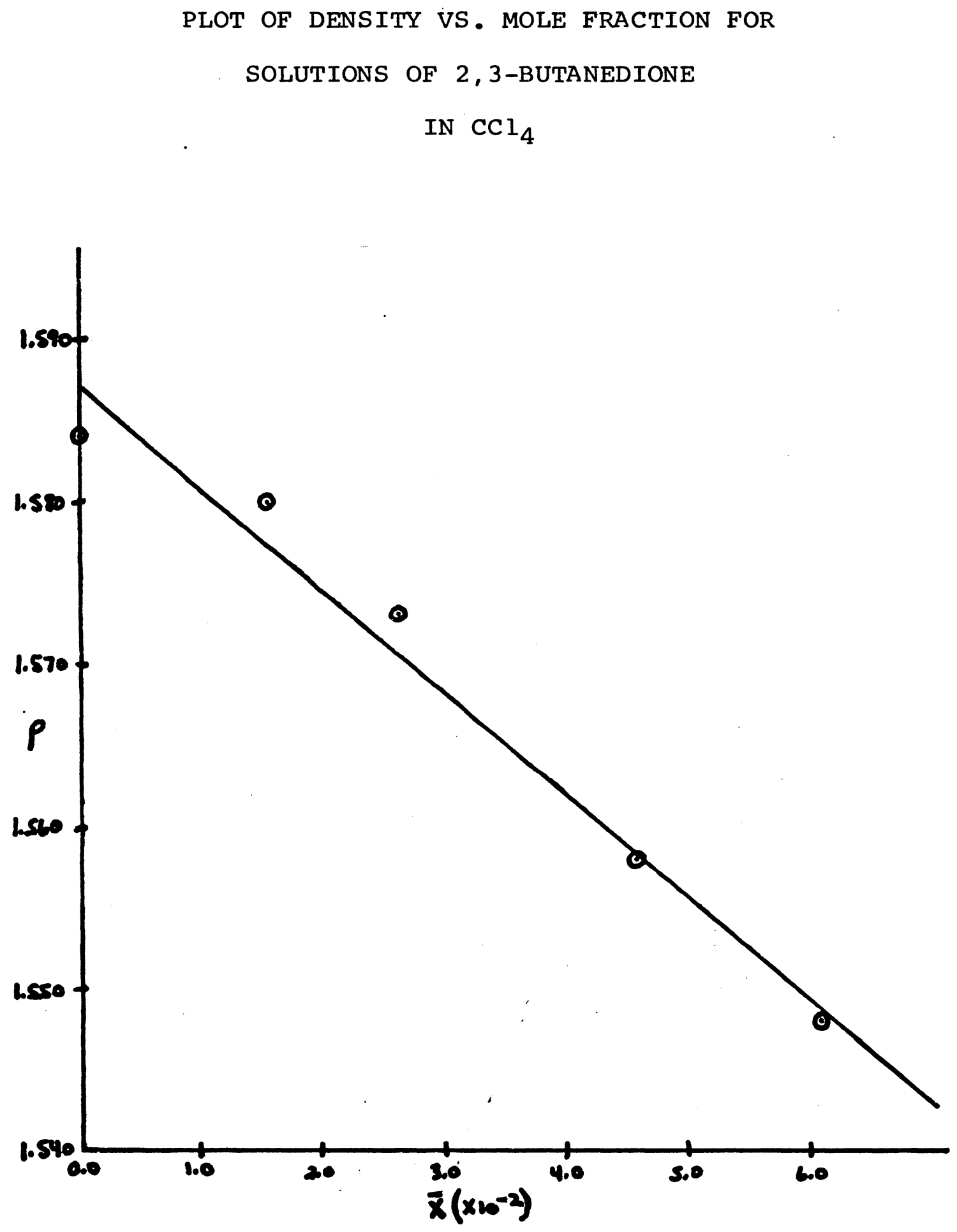
Vapor-Phase Measurements

A nitrogen gas calibration was needed for gas phase measurements at each temperature. Typical calibration data is presented in Table V, which was taken from an experiment at $310.15^{\circ} \mathrm{K}$.

Table V

\begin{tabular}{lcc}
\hline$P(\mathrm{~atm})$ & $\delta$ & $\epsilon-1\left(\times 10^{-4}\right)$ \\
\hline 0.5287 & 3748.4 & 2.734 \\
0.4632 & 3728.1 & 2.395 \\
0.3961 & 3704.1 & 2.048 \\
0.3305 & 3678.2 & 1.709 \\
0.2645 & 3661.0 & 1.368 \\
\hline
\end{tabular}

Symbols used are $\mathrm{P}$ represents pressure of nitrogen gas, $S$ represents corrected average dial setting, and $\epsilon$ represents the dielectric constant. The corresponding calibration curve is presented in Figure 10. In Table V, values for $\epsilon-1$ were obtained from the clausius-Mosotti equation. (See Appendix 3)

$$
\begin{aligned}
E-1= & 3 P_{M} \frac{P}{1000 R T} \\
\text { where } P_{M} & =\text { molar polarization of } \mathrm{N}_{2} \text { gas } \\
& =4.387 \mathrm{cC} \text { at } 293.15^{\circ} \mathrm{K} \\
\mathrm{R} & =\text { gas constant } \\
& =0.082054 \text { 1-atm } / \text { mole- }{ }^{\circ} \mathrm{K} \\
\mathrm{T} & =\text { temperature in }{ }^{\circ} \mathrm{K} \\
\mathrm{P} & =\text { pressure in atmospheres }
\end{aligned}
$$


Figure 10

Calibration Curve for Nitrogen Gas at $310.15^{\circ} \mathrm{K}$ 


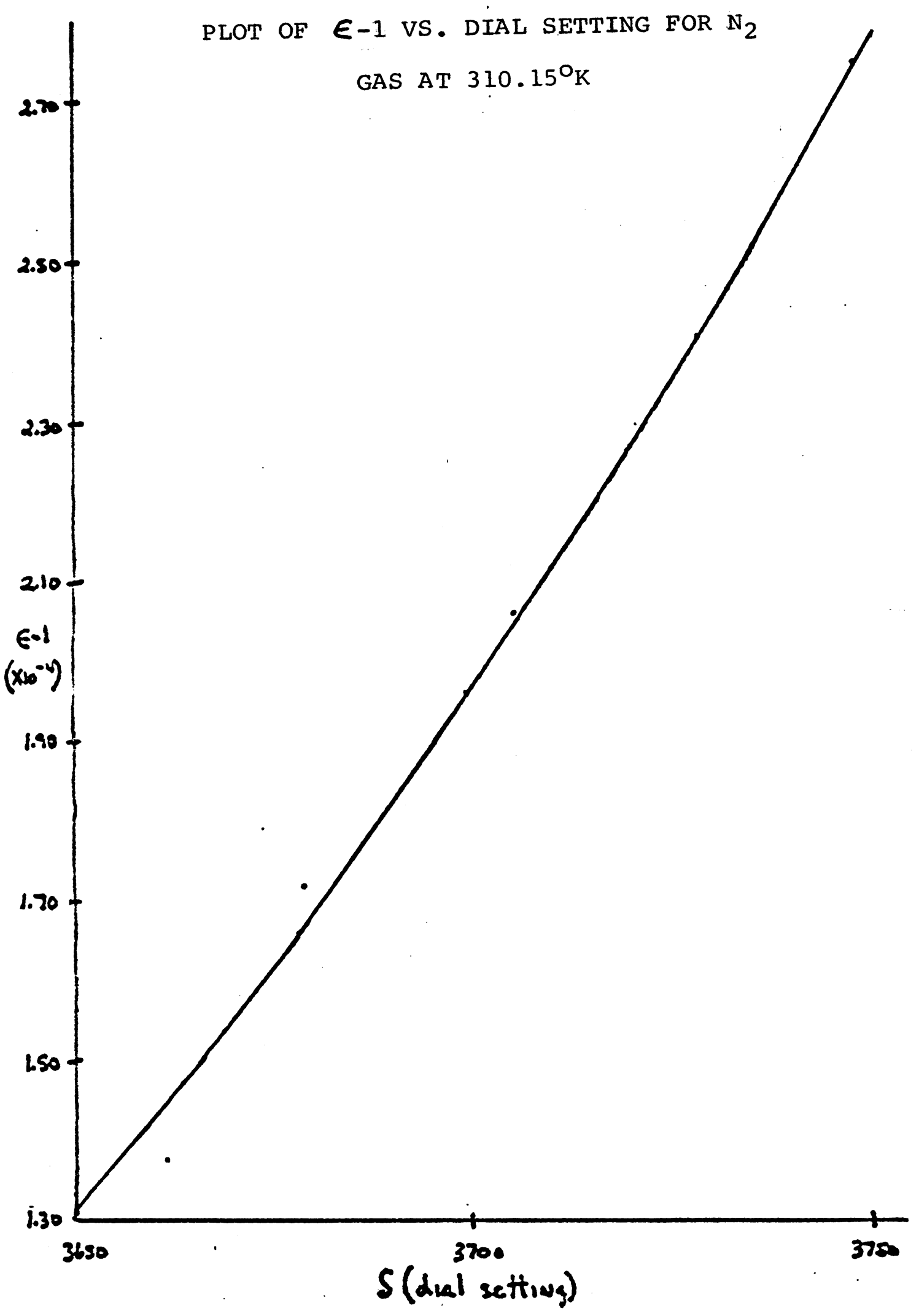


A second ordered polynomial using a nonlinear least squares fit (See Appendix 2) was found to fit all the calibration curves. The equation for the calibration curve in the preceding table is

$$
\begin{aligned}
\epsilon-1=A_{0}+A_{1} \boldsymbol{S}+\boldsymbol{A}_{2} \boldsymbol{S}^{2} \\
\text { where } A_{0}=0.3608931 \times 10^{-1} \\
A_{1}=-0.2089099 \times 10^{-4} \\
A_{2}=0.3024361 \times 10^{-8}
\end{aligned}
$$

The dielectric constant for 2,3-butanedione is then calculated from its dial setting, its pressure, and the above calibration equation. The molar polarization for 2,3-butanedione was then calculated from the data presented in Table VI.

\section{Table VI}

\begin{tabular}{ccr}
\hline$\delta$ & $\epsilon-1\left(\times 10^{-4}\right)$ & $P($ atm $)$ \\
\hline 3709.9 & 2.141 & .04105 \\
3720.1 & 2.296 & .04105 \\
3705.9 & 2.050 & .04079 \\
\hline
\end{tabular}

Symbols used are $\boldsymbol{S}$ représents dial setting, $\epsilon$ represents dielectric constant, and $\mathrm{P}$ represents pressure in atmospheres.

$$
\begin{gathered}
P_{m}=\frac{(\epsilon-1)(R T) 1000}{3 P} \\
\text { where } P_{m}=\text { molar polarization } \\
\epsilon=\text { dielectric constant } \\
R=\text { gas constant }
\end{gathered}
$$




$$
\begin{aligned}
& \mathrm{T}=\text { temperature in } \mathrm{O}_{\mathrm{K}} \\
& \mathrm{P}=\text { pressure in } \mathrm{atm} .
\end{aligned}
$$

The dipole moment was then calculated using the Debye Equation. (See Appendix 3)

$$
\begin{aligned}
\mathrm{P}_{\mathrm{m}}=\mathrm{P}_{d} & +\frac{4 \pi \mathrm{N}_{0} \mu^{2}}{9 k T} \\
\text { where } \mathrm{P}_{\mathrm{m}} & =\text { molar polarization } \\
\mathrm{P}_{\mathrm{d}} & =\text { distortion polarization } \\
& =22.99 \\
\mathrm{~N}_{\mathrm{o}} & =\text { Avagadro's number } \\
& =6.0229 \times 10^{23} \\
\mathrm{k} & =\text { Boltzmann constant } \\
& =1.38044 \times 10^{23} \\
\mathrm{~T} & =\text { temperature in }{ }^{\circ} \mathrm{K} \\
\mu & =\text { dipole moment }
\end{aligned}
$$

All results made in the vapor phase for 2,3butanedione are summarized in Table VII. 
Table VII

\begin{tabular}{lcccc}
\hline \hline $\mathrm{T}\left({ }_{\mathrm{K}}\right)$ & $\boldsymbol{\epsilon}-1\left(\times 10^{-4}\right)$ & $\mathrm{P}(\mathrm{atm})$ & $\mathrm{P}_{\mathrm{m}}$ & $\mu$ \\
\hline 310.15 & 2.296 & $.04105 \pm .00013$ & 46.97 & $1.11 \pm .05$ \\
310.15 & 2.238 & .04289 & 44.26 & 1.04 \\
310.15 & 2.141 & .04105 & 43.64 & 1.02 \\
310.15 & 2.050 & .04079 & 42.63 & 1.00 \\
330.15 & 2.050 & .04158 & 44.52 & 1.08 \\
330.15 & 1.955 & .04237 & 41.67 & 1.01 \\
350.15 & 1.959 & .04211 & 44.56 & 1.11 \\
350.15 & 1.793 & .04158 & 41.30 & 1.03 \\
370.15 & 1.807 & .04237 & 43.18 & 1.11 \\
370.15 & 1.681 & .04158 & 40.93 & 1.04 \\
390.15 & 1.673 & .04421 & 40.37 & 1.05 \\
390.15 & 1.672 & .04211 & 42.38 & 1.11 \\
390.15 & 1.618 & .04211 & 41.01 & 1.07 \\
390.15 & 1.606 & .04263 & 40.19 & 1.05 \\
390.15 & 1.591 & .04053 & 41.89 & 1.10 \\
390.15 & 1.586 & .04211 & 40.20 & 1.05 \\
431.35 & 1.409 & .04000 & 41.56 & 1.15 \\
431.35 & 1.348 & .04105 & 38.74 & 1.06 \\
431.35 & 1.274 & .03921 & 38.33 & 1.04 \\
432.04 & 1.537 & .04000 & 45.41 & 1.26 \\
432.04 & 1.326 & .04079 & 38.41 & 1.05 \\
472.10 & 1.349 & .04026 & 43.26 & 1.25 \\
472.10 & 1.251 & .04026 & 40.12 & 1.15 \\
472.10 & 1.248 & .04158 & 38.76 & 1.11 \\
& & & & \\
\hline
\end{tabular}

Symbols used are $\mathrm{T}$ represents temperature, $\epsilon$ is dielectric constant, $P$ is preśsure, $P_{m}$ is molar polarization, and $\boldsymbol{\mu}$ is dipole moment. 


\section{DISCUSSION}

\section{Comparison of Results with other Dipole Studies}

Dipole measurements have been carried out on 2,3-butanedione on two occasions prior to this experimental work (Zahn in $1932^{6}$ and Bloom and Sutton in 19417). These results are compared in Figure 11. It can be seen that a serious discrepancy existed between Zahn's data and Bloom and Sutton's. The results of our vapor phase measurements are in best agreement with Bloom and Sutton's data. Moreover, both Le Fevre ${ }^{12}$ and these solution dipole measurements of 2,3-butanedione are in good agreement with Bloom and Sutton's vapor phase measurement extrapolated to $298^{\circ} \mathrm{K}$ : Bloom and Sutton's extrapolated dipole equals $1.01 \mathrm{D}$; Le Fevre's solution dipole equals $1.02 \mathrm{D}^{\mathrm{a}}$; these solution measurements equals $1.03 \mathrm{D}$. Since Zahn gives no experimental details, it can only be speculation as to why his results are inaccurate. Sample impurities are the most likely cause for inaccuracies in dipole measurements. Contamination of either the 2,3-butanedione or the dielectric calibration gas could result in the anomalously high dipole reported by Zahn.' Since the error seems to be of a systematic nature throughout the entire experiment,

atomic Polarization was neglected in Le Fevre's dipole calculation $(\vec{\mu}=1.04 \mathrm{D})$. This value was obtained from the approximation $\mathrm{P}_{\mathrm{d}}=1.1 \mathrm{R}_{\mathrm{m}}=\mathrm{P}_{\mathrm{E}}+\mathrm{P}_{\mathrm{A}}$ where $R_{m}=\frac{m^{2}-1}{m^{2}+2}\left(\frac{m}{p}\right)=20.7 \mathrm{cc}$ 
Figure 11

Comparison of Results with other Dipole Studies 


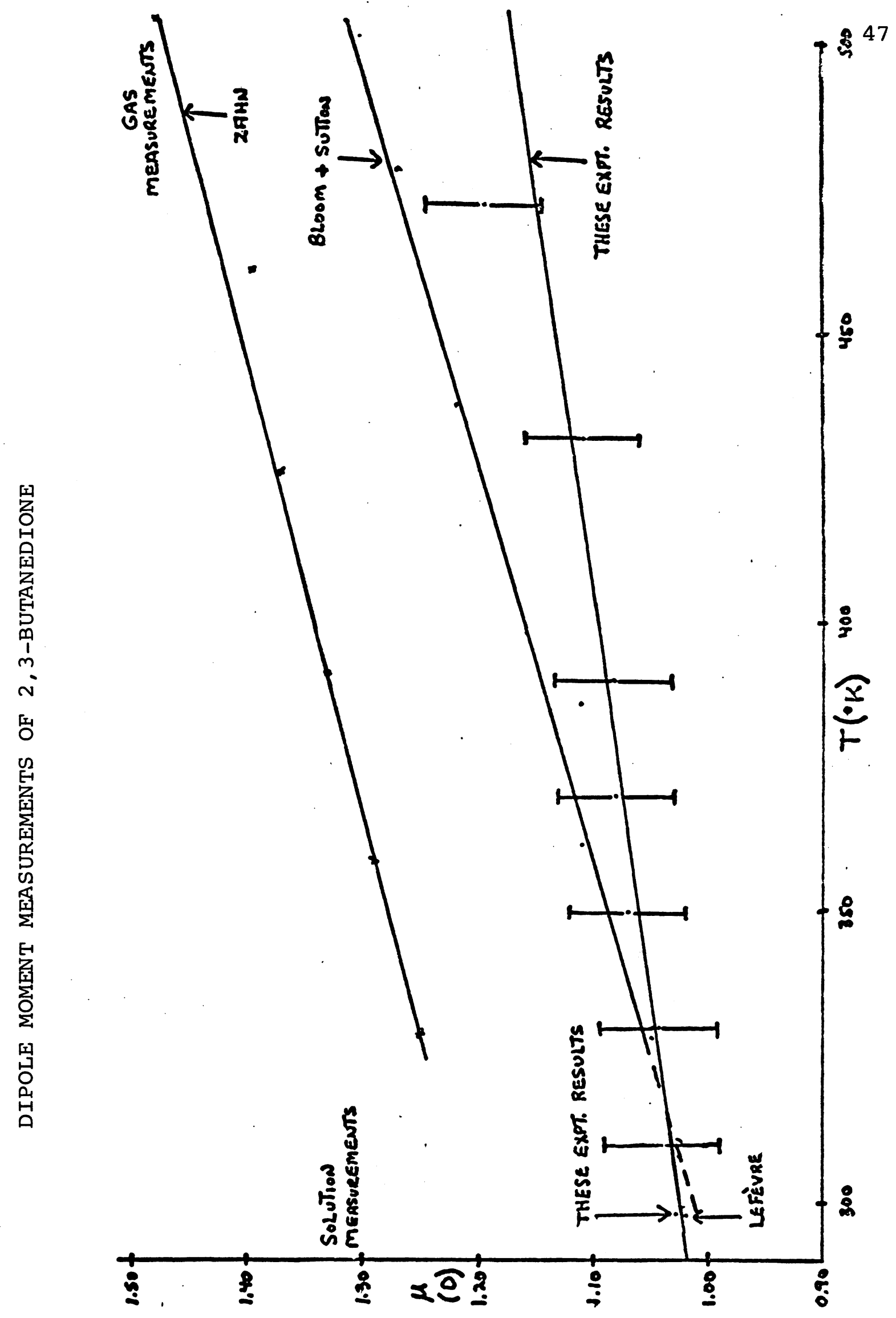


it would seem that the problem was one of dielectric standardization.

At low temperatures, there is good correlation between Bloom and Sutton's and these vapor phase studies. As higher temperatures are attained, Bloom and Sutton's dipole measurements increase at a more rapid rate. When comparing the two sets of data, it appears that Bloom and Sutton's data has much better precision. However, the accuracy of their measurements is questionable, since they reported difficulty in the synthesis and purification of their 2,3-butanedione.

The sample used in these measurements was already of high purity when purchased from the Eastman Kodak Company. Further purification was obtained by twice fractionally distilling the sample.: Since the sample used in these measurements was of very high purity, it is believed that the results obtained in our measurements are accurate.

\section{Dipole Moment and Intramolecular Rotation}

For molecules which contain a single fixed dipole, the dipole moment is calculated by

$$
\begin{aligned}
\vec{\mu}=q & \vec{r} \\
\text { where } q & =\text { charge } \\
r & =\text { distance of charge separation } \\
\vec{\mu} & =\text { dipole moment }
\end{aligned}
$$

In molecules containing several fixed dipoles, the 
dipole moment calculation becomes more complicated. ${ }^{13}$ For this case a set of reference axes in the molecule must be chosen and the dipole component along each axis calculated. The resultant dipole moment is then obtained by summing the squares of the component sums $\mathrm{m}_{\mathrm{x}}, \mathrm{m}_{\mathrm{y}}$, and $\mathrm{m}_{\mathrm{z}}$ along each axis and taking the square root, that is

$$
\vec{u}=\left(m_{x}^{2}+m_{y}^{2}+m_{z}^{2}\right)^{\frac{1}{2}}
$$

Equation (1) is also a good approximation for molecules that contain dipoles that are free to rotate and all positions of rotation are equally probable. However, in molecules where there are two rotatable dipoles on adjacent carbon atoms such as found in 1,2-dicarbonyls, then equation (1) generally cannot be employed. In these cases, the dipole moment depends on the shape of the torsional potential function. Molecules of high potential energy are statistically unfavored and make smaller contributions to the observed dipole. The observed moment is then lower than the value calculated by equation (1) and tends to increase with temperature. The temperature dependence of the dipole moment is good evidence that rotation about the chemical bond is hindered. No temperature dependence of the dipole moment will be observed for cases where free rotation of the dipoles is present and all positions around the $\mathrm{C}-\mathrm{C}$ are equally probable. In cases where the trans isomer is of lower energy than the cis isomer i.e. rotation is hindered by a potential barrier, then thermal effects will be observed in 
the dipole measurements. As the temperature of the sample increases, the population of the cis isomer becomes statistically more favored. Therefore an increase in temperature results in a higher Boltzmann population of polar molecules and an increase in the observed dipole moment.

At this point, a more in depth look at the calculation of the dipole moment for 1,2-dicarbonyl compounds must be undertaken. For the more general case where there are two dipoles on adjacent carbons as shown below

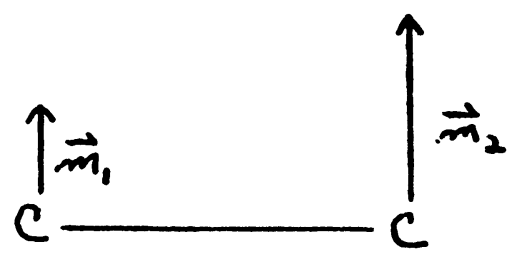

where $\mathrm{m}_{1}$ and $\mathrm{m}_{2}$ represent the components of the resultant dipole moment for each carbonyl group, perpendicular to the C-C bond axis. The total dipole moment is found by vectorially summing up the two dipoles.

$$
\vec{\mu}=\left(\vec{m}_{1}+\vec{m}_{2}\right)
$$

Dipole moments cannot be measured directly in the laboratory but instead must be obtained from dielectric measurements. However, the measured dielectric constant is sensitive to the square of the dipole moment rather than the dipole as shown by equation (3). (See Appendix 3)

$$
\frac{\epsilon-1}{\epsilon+2}\left(\frac{m}{\rho}\right)=\frac{4 \pi}{3} N_{0}\left(\alpha_{0}+\frac{\vec{\mu}^{2}}{3 k T}\right)
$$


The square of the dipole moment is equal to the dot product of the sum of the dipoles.

$$
\vec{u}^{2}=\left(\vec{m}_{1}+\vec{m}_{2}\right) \cdot\left(\overrightarrow{m_{1}}+\vec{m}_{2}\right)
$$

Upon solving, equation (4) becomes

$$
\vec{\mu}^{2}=m_{1}^{2}+m_{2}^{2}+2 m_{1} m_{2} \cos \phi
$$

where $\phi$ is defined in the diagram below. Note that the direction associated with the dipole moments has been lost when taking the dot product.

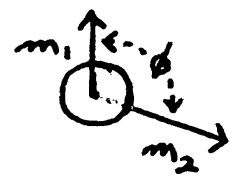

Introducing $A$ and $B$, where $A=m_{1}^{2}+m_{2}^{2}$ and $B=2 m_{1} m_{2}$, yields for the molecular dipole (See Appendix 4)

$$
\vec{u}^{2}=A+B \cos \phi
$$

This equation gives the dipole moment for only one torsional angle about the C-C bond. Classically there should be no constraint put on the torsional angle and the square of the observed dipole moment can be calculated by allowing $\cos \phi$ to be averaged over all possible orientations, that is

$$
\left\langle\vec{\mu}^{2}\right\rangle=A+B\langle\cos \phi\rangle
$$

When solving the' $\langle\cos \phi\rangle$ term, each possible 
configuration of the molecule must be accounted for by taking a Boltzmann distribution of the molecules as a function of the torsional potential angle such that

$$
N(\phi)=e^{-\frac{v(\phi)}{k T}}
$$

where $N(\phi)=$ number of molecules with angle $\phi$

$$
k=\text { Boltzmann constant }
$$

and averaging over all possible configurations resulting in

$$
\langle\cos \phi\rangle=\frac{\int_{0}^{\pi} \cos \phi e^{-\frac{v(\phi)}{h T}} d \phi}{\int_{0}^{\pi} e^{-\frac{v(\phi)}{k T} d \phi}}
$$

$$
\left\langle\vec{\mu}^{2}\right\rangle=A+B \frac{\int_{e}^{\pi} \cos \phi e^{-\frac{v(\phi)}{h T}} d \phi}{\int_{0}^{\pi} e^{-\frac{v(\Phi)}{k T}} d \phi}
$$

where $V(\phi)$ represent the torsional potential function. The nature of this function will be discussed in the following section.

\section{Torsional Potential Model}

For 1,2-dicarbonyl compounds of the general form

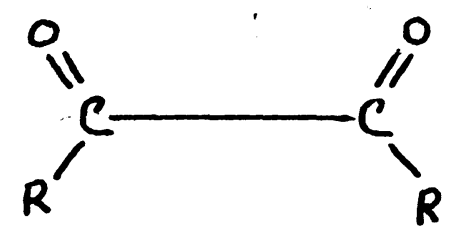

at least five different, types of intramolecular forces 
contribute to the torsional potential. 'The following coordinate system below will be used to describe the angular dependence of these interactions in the following discussion.

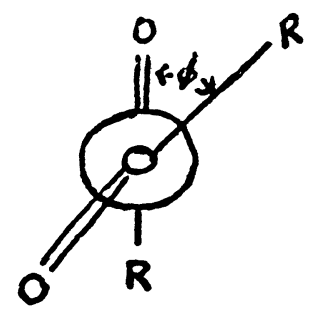

Note that the torsional angle $\phi$ is zero for the trans configuration.

Both attractive and repulsive intramolecular forces contribute to the total torsional potential. Dipoleinduced dipole, van der Waals, and pi-bonding are all attractive forces. The dipole-induced dipole force occurs when the permanerit dipole associated with a carbonyl group induces an oppositely oriented dipole in the adjacent carbonyl group resulting in an attractive force. (See diagram below)

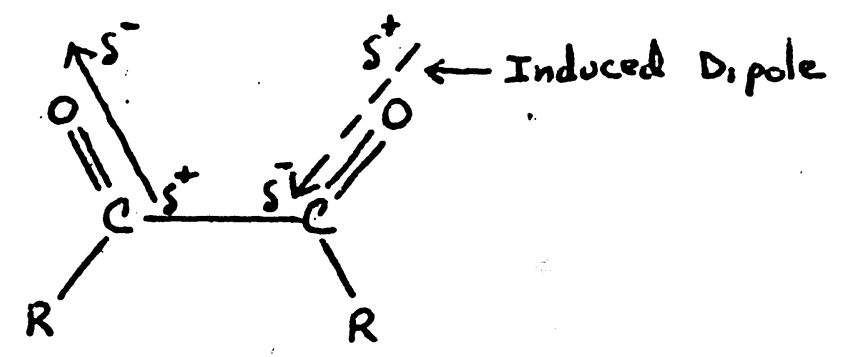

Attractive van der Waals forces result from interactions between dipoles in one carbonyl group induced by a temporary dipole in the adjacent carbonyl group. These small temporary instantaneous dipoles arise from rapid motion of the charge density along the highly polarizable carbonyl functional group. Van der Waals forces and dipole-induced dipole forces will both give a potential 
energy curve that is qualitatively the same and is shown in Figure 12.1. A single parameter potential function expressed in the form $\frac{V I}{2}(1-\cos \phi)$ can be used to represent these interactions where Vl represents the height of the potential curve. The third type of attractive force found is due to p-orbital overlap. In forming the $\mathrm{sp}^{2}$ hybridized carbonyl carbon atoms, one p-orbital containing a single electron remains unused. This p-orbital consists of two equal lobes of charge density oriented perpendicular to the plane of the three $\mathrm{sp}^{2}$ orbitals. A molecular orbital description of these molecules shows partial pi-bonding between these carbonyl atoms due to p-orbital overlap.

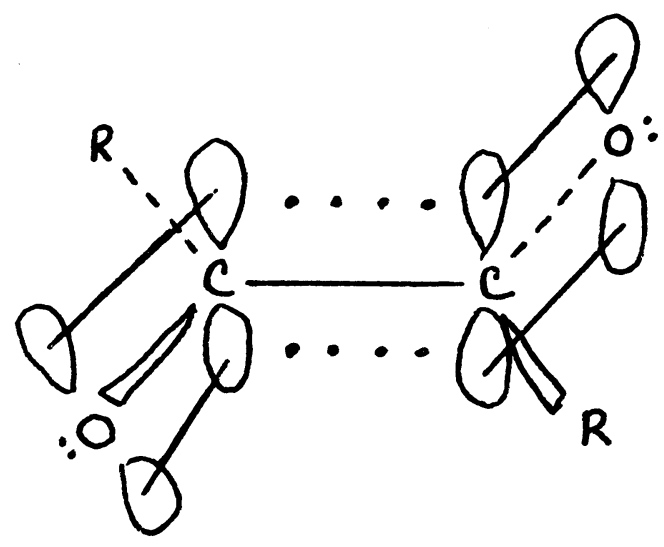

A plot of the potential energy curve for the p-orbital overlap (See Figure 12.3) is found to be quite different than for the other attractive forces. This difference is due to the fact that the attractive forces associated with the p-orbital overlap are periodic in every $180^{\circ}$. This potential curve exhibits a $\cos 2 \phi$ angular dependence. Thus the potential of the form $\frac{\sqrt{2}}{2}(1-\cos 2 \phi)$ provides an 
Figure 12

Angular Dependence of Three One-Parameter

Potential Functions 


$$
\frac{W W}{W}
$$


approximate description of the interaction due to p-orbital overlap.

In contrast to the attractive forces previously mentioned, dipole-dipole and steric forces are repulsive. The nature of the dipole-dipole interaction can be seen from the diagram below.

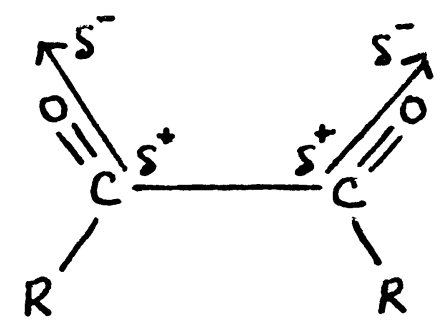

The permanent dipoles of the adjacent carbonyl groups prefer an orientation with the carbonyl oxygens as far away as possible on the basis that like charges will repel each other. Steric forces will also be of a repulsive nature in 1,2-dicarbonyl compounds. As the $\mathrm{R}$ groups become more bulky and crowding results, then the repulsive forces associated with the steric strain increases causing the groups to want to be as far away from each other as possible. For very bulky groups the trans configuration would relieve this strain and be most favored.

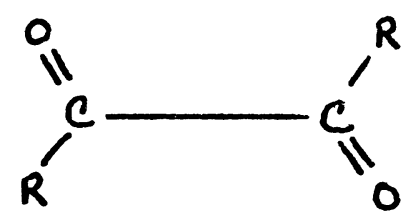


Both dipole-dipole and steric forces can be qualitatively represented by the potential curve in Figure 12.2. It should be pointed out that differences between the curves in Figure 12.1 and Figure 12.2 are due to the nature of the forces involved. With attractive forces the sign of $\mathrm{VI}$ in $\frac{v l}{2}(1-\cos \phi)$ will be positive, whereas repulsive forces result in a negative $\mathrm{Vl}$.

After analyzing all of the intramolecular forces associated with 1,2-dicarbonyl compounds, it is now apparent that a two parameter potential must be used for the potential energy function. A potential model may best be expressed as $v(\phi)=\frac{V_{1}}{2}(1-\cos \phi)+\frac{V_{2}}{2}(1-\cos 2 \phi)$. The $\frac{\mathrm{Vl}}{2}(1-\cos \phi)$ term is associated with van der Waals, dipole-induced dipole, dipole-dipole, and steric forces. The second term $\frac{V_{2}}{2}(1-\cos 2 \phi)$ is associated with forces due to p-orbital overlap.

The cis isomer of glyoxal, the simplest 1,2-dicarbonyl compound, has been experimentally observed on two different occasions (Currie and Ramsey in $1970^{1}$ and Durig, Tong, and $\mathrm{Li}$ in $1972^{2}$ ). Upon considering the structure of glyoxal it is evident that

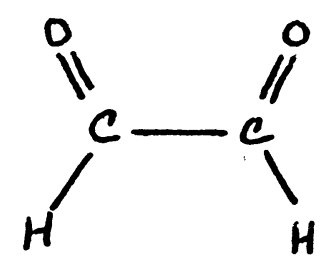

steric factors between the hydrogen atoms will be 
negligible. This lack of steric forces which in turn allows for greater contributions of the V2 term associated with p-orbital overlap may account for the existence of the cis isomer of glyoxal. In contrast, the cis isomer of 2,3-butanedione, the next simplest 1,2-dicarbonyl compound, has not been experimentally observed. All existing experimental evidence (ir, uv, and electron diffraction) indicates that

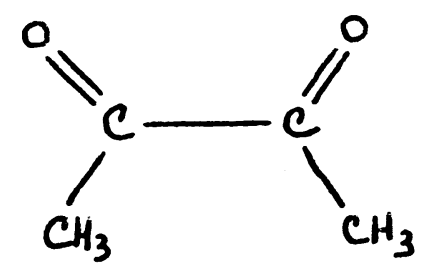

2,3-butanedione exists only in the trans form. It will be shown that this dipole study supports these findings.

Determination of Potential Parameters

Since an expression for the potential function, $\mathrm{V}(\boldsymbol{\beta})$, has been obtained, equation (9) can be written in the $\left\langle\vec{\mu}^{2}\right\rangle=A+B \frac{\int_{0}^{\pi} \cos \phi e^{\frac{-\left[\frac{v_{1}}{2}(1-\cos \phi)+\frac{v_{2}}{2}(1-\cos 2 \phi)\right]}{k T}} d \phi}{\int_{0}^{\pi} e^{-\frac{\left[\frac{v_{1}}{2}(1-\cos \phi)+\frac{v^{2}}{2}(1-\cos 2 \phi)\right]}{k T}} d \phi}(10)$

The potential parameters $\mathrm{V} 1$ and $\mathrm{V} 2$ that best fit the experimental dipole moment measurements can be found from the above equation. This is accomplished by calculating dipole moments as a function of temperature for 
specific values of $\mathrm{VI}$ and $\mathrm{V} 2$, which were systematically varied.

The integrals in equation (10) were evaluated by numerical methods on an IBM-360 computer using Simpson's rule. (See Appendix 2) A search grid of $1500 \mathrm{~cm}^{-1}<\mathrm{VI}$ $<3500 \mathrm{~cm}^{-1}$ and $0 \mathrm{~cm}^{-1}<\mathrm{v} 2<600 \mathrm{~cm}^{-1}$, using increments of $\Delta \mathrm{Vl}=10 \mathrm{~cm}^{-1}$ and $\Delta \mathrm{V} 2=10 \mathrm{~cm}^{-1}$, requires the evaluation of more than a million integral areas.

The calculated dipoles are compared to the experimental values to assess the quality of the potential parameters. The results of each comparison can be expressed by a regression value (R)

$$
R=\sum_{i=1}^{n} S_{i}^{2}
$$

where $S=$ the difference between the calculated dipoles and observed dipoles. The regression (R) will equal zero when the experimental and calculated dipoles are equal. Hence, the best potential parameters correspond to a minimum regression. A regression contour map best illustrates the results of this parameter search. (See Figure 13) The precision of these dipole measurements allows the best values for the V1 and V2 potentials to lie anywhere within the regression equal to 0.015 . The best regression fit corresponds to $\mathrm{Vl}=2890 \mathrm{~cm}^{-1}$ and $\mathrm{V} 2=0.0 \mathrm{~cm}^{-1}$. 
Figure 13

Regression Contours for $R=0.05,0.03,0.02$, and 0.015 .

Also Included Are Electron Diffraction and Infrared

Constraints for V1 and V2 (See "Potential

Parameters from other Methods"

in Discussion) 


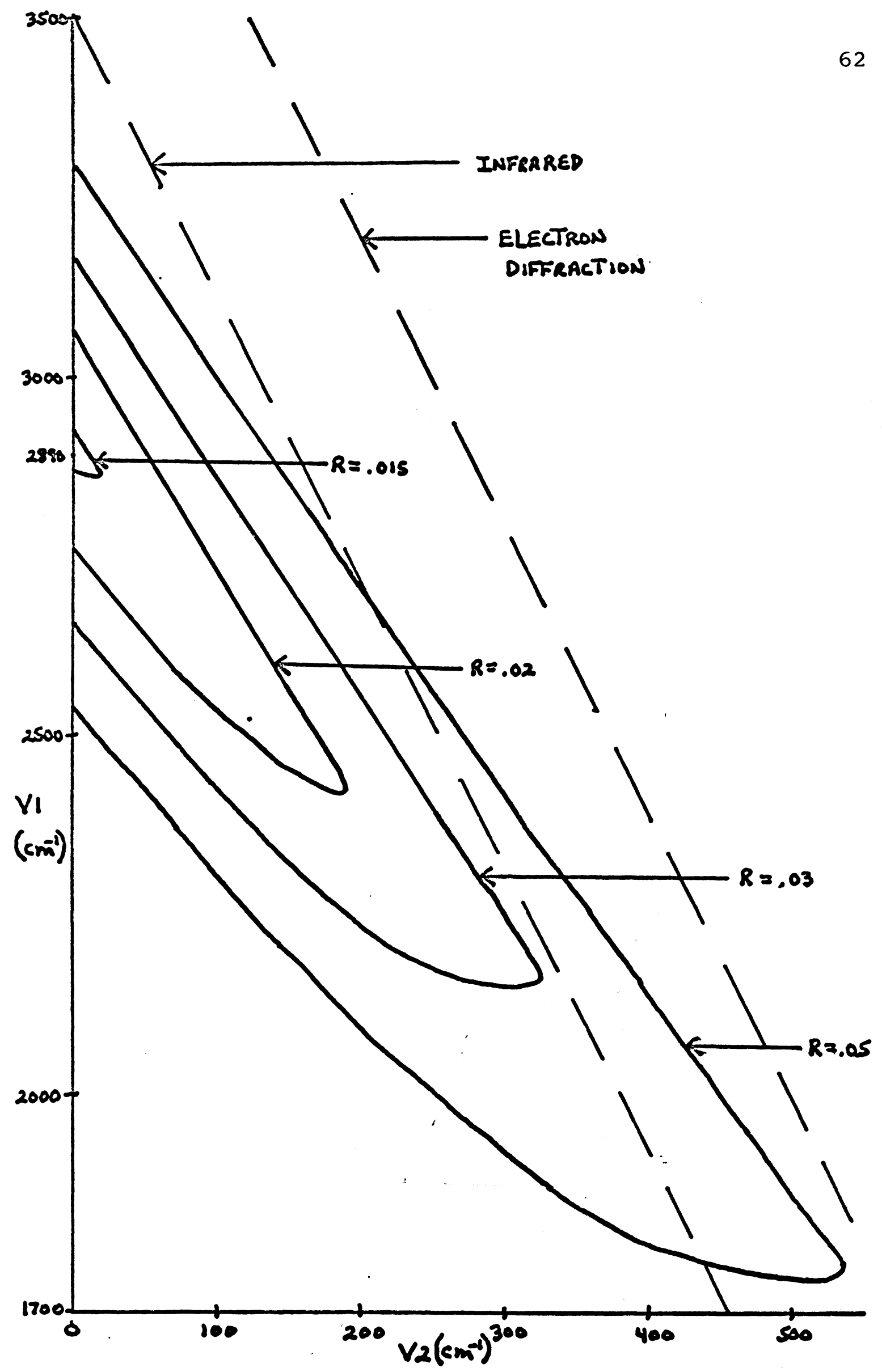


Potential Parameters from other Methods

Values for the potential parameters V1 and V2 have been estimated from infrared ${ }^{3,4}$ and electron diffraction ${ }^{5}$ data. In both cases, these values were calculated from the harmonic oscillator model. This model assumes that the torsional vibrational spacings are governed by a parabolic potential function. Indeed a cosine function can be approximated by a parabola near its minimum value. If a cosine function is expanded in a power series, then it becomes

$$
\cos \phi=1-\frac{\phi^{2}}{2 !}+\frac{\phi^{4}}{4 !}-\frac{\phi^{6}}{6 !}+\cdots \cdot
$$

For cases where the angle $\phi$ is small, then the higher order terms can be neglected and the series truncated at the second order term.

In earlier discussion, the potential function for 1,2-dicarbonyl compounds was found to be described by

$$
v(\phi)=\frac{v_{1}}{2}(1-\cos \phi)+\frac{v_{2}}{2}(1-\cos 2 \phi)
$$

This equation can then be rewritten in the following manner

$$
v(\phi)=\frac{v_{1}}{4} \phi^{2}+v_{2} \phi^{2}
$$

after substituting the expression given in equation (11) for the $\cos \phi$ term. Upon simplification, equation (13) 
can be rewritten

$$
v(\phi)=\frac{1}{4}\left(v_{1}+4 v_{2}\right) \phi^{2}
$$

If $V^{*}$ is introduced to represent the quantity $\mathrm{VI}+4 \mathrm{~V} 2$ :

$$
\mathrm{V} *=\mathrm{V} 1+4 \mathrm{~V} 2
$$

This allows equation (14) to now be written

$$
v(\phi)=\frac{1}{4}\left(v^{*}\right) \phi^{2}
$$

which is the expression given for the harmonic oscillator having the force constant

$$
\begin{gathered}
k=\frac{V^{*}}{2} \\
\text { i.e. } v(\phi)_{H_{0}}=\frac{1}{2} k \phi^{2}=\frac{1}{2}\left(\frac{v^{*}}{2}\right) \phi^{2}
\end{gathered}
$$

In addition, the frequency of oscillation can also be related to the force constant and reduced moment of inertia in the following manner: 15

$$
\bar{\nu}=\frac{1}{2 \pi} \sqrt{\frac{k}{\mu_{I}}}
$$

$$
\text { where } \begin{aligned}
\mu_{\mathbf{x}} & =\text { reduced moment of inertia } \\
\mathrm{k} & =\text { force constant } \\
& \boldsymbol{\nu}=\text { frequency of oscillation }
\end{aligned}
$$


Substituting $V * / 2$ for $k$, equation (18) becomes

$$
\bar{\nu}=\frac{1}{2 \pi} \sqrt{\frac{v^{*} / 2}{k_{1}}}
$$

From equation (19), the value for $V^{*}$ can then be obtained by measuring the torsional transition frequency, $\bar{v}$, associated with the torsional mode about the $\mathrm{C}-\mathrm{C}$ bond. Using infrared data, $4 a V^{*}$ has been reported as $3520 \mathrm{~cm}^{-1}$, whereas electron diffraction ${ }^{5}$ analysis found it to be equal to $3989 \mathrm{~cm}^{-1}$. Values of $\mathrm{V} 1$ and $\mathrm{V} 2$ that satisfy the infrared and electron diffraction for $\mathrm{V}$ * are shown as straight lines in Figure 13.

From dipole moment data, the best regression fit of the potential parameters gave values of $\mathrm{Vl}=2890 \mathrm{~cm}^{-1}$ and $\mathrm{V} 2=0.0 \mathrm{~cm}^{-1} . \mathrm{a}$ When comparing these values with other experimental results, it can be seen that a wide variation exists in the three values for V1 when V2 equals zero.

$$
\mathrm{VI}\left(\mathrm{cm}^{-1}\right)
$$

Dipole Moment

Electron Diffraction 5 Infrared 4 2890.0 3989.0 3520.0 $\underline{\mathrm{V} 2}\left(\mathrm{~cm}^{-1}\right)$ 0.0 0.0 0.0

This discrepancy may be attributed to approximations that are made in obtaining the values for $V 1$ and V2 using

\footnotetext{
a The pest fit of Bloom and Sutton's data gave $\mathrm{Vl}=2630 \mathrm{~cm}^{-1}$ and $\mathrm{V} 2=0.0 \mathrm{~cm}$.
} 
infrared and electron diffraction. Treating the torsional potential curve like a true harmonic oscillator is a poor approximation, at best, since any anharmonicity present in the potential has been neglected. Moreover, the absorption maximum has been interpreted as a single transition $(\nu=1 \leftarrow \nu=0$ ) as shown below.

HO MODEL

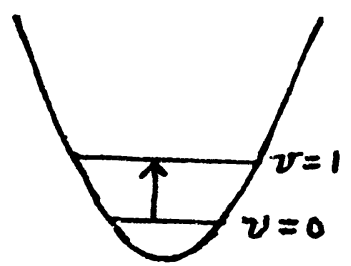

TORSIONAL POTENTIAL

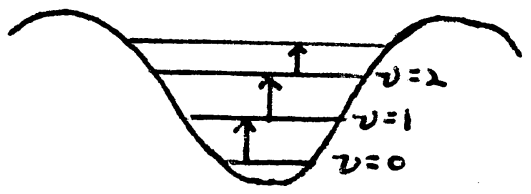

This would be true if only the lower torsional vibrational level was populated. Since the vibrational spacings, $\left(\Delta E \cong 50 \mathrm{~cm}^{-1}\right),{ }^{a}$ is much smaller than $\mathrm{kT}$, all of the vibrational levels are significantly populated in accordance with a Boltzmann distribution. This results in the torsional absorption spectrum made up of several closely spaced transitions. Therefore, the $1 \leftarrow 0$ torsional transition of interest should lie at a lower value than reported. (See Diagram Below) Since this torsional

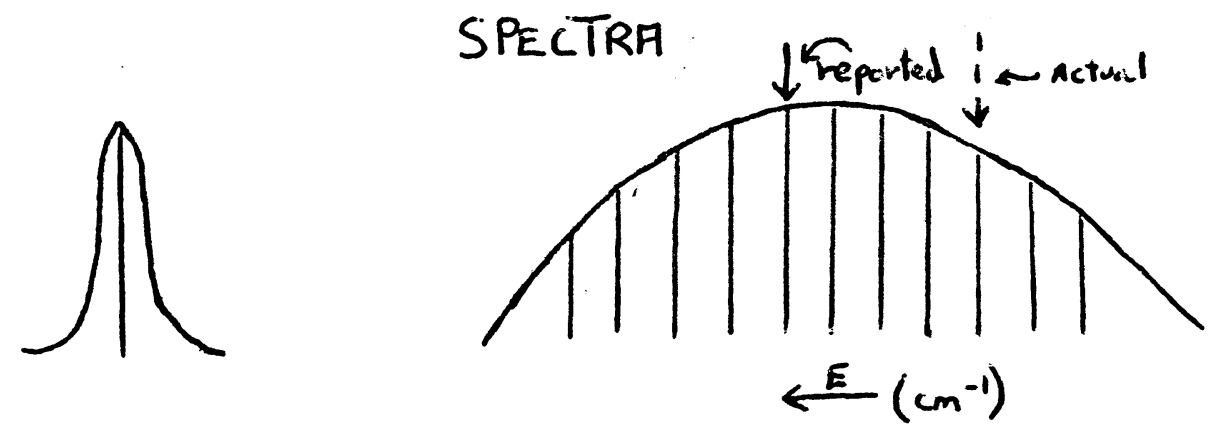

$$
{ }^{\mathrm{a}} \text { Durig et al }{ }^{3} \text { report } \bar{\nu}=52 \mathrm{~cm}^{-1} \text {, Fately et al }{ }^{4 a}
$$
and Harris et al $4 \mathrm{~b}$ report $\bar{\nu}=48 \mathrm{~cm}^{-1}$. 
transition is at a very low energy (approximately $50 \mathrm{~cm}^{-1}$ ). a small uncertainty in the reported transition frequency can have large affects on the value for $V^{*}$ and likewise on the potentials $\mathrm{V} 1$ and $\mathrm{V} 2$.

Using the optimum potential parameters determined from the temperature dependence of the dipole moment, $\mathrm{Vl}=2890 \mathrm{~cm}^{-1}$ and $\mathrm{V} 2=0.0 \mathrm{~cm}^{-1}$, the harmonic oscillator torsional frequency can be calculated from equation (15) and (19) as $\bar{\nu}=44 \mathrm{~cm}^{-1}$. This frequency is indeed compatitable with the observed far infrared absorption.

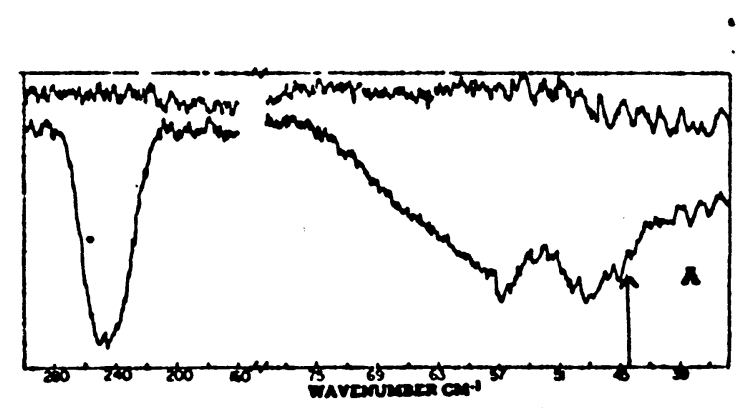

The Far IR spectrum of 2,3-butanedione, reproduced from Durig, Hannum and Brown, Journal of Physical Chemistry, LXXV (1971), 1953. The arrow at $44 \mathrm{~cm}^{-1}$ corresponds to the $1 \leftarrow 0$ harmonic transition frequency calculated from this dipole moment study.

This dipole study provides convincing theoretical evidence that the cis isomer of 2,3-butanedione is unstable. The regression contours derived from these measurements indicates that the intramolecular forces that are periodic in $2 \pi$ are very small. Hence, spectroscopic detection of the cis isomer would seem highly improbable. The limiting potentials derived from this study are depicted in the. Figure 14.1. It is of interest to compare the 
Figure 14

Limiting Potential Energy Curves for Internal Rotation in 2,3-Butanedione Compared with Glyoxal 


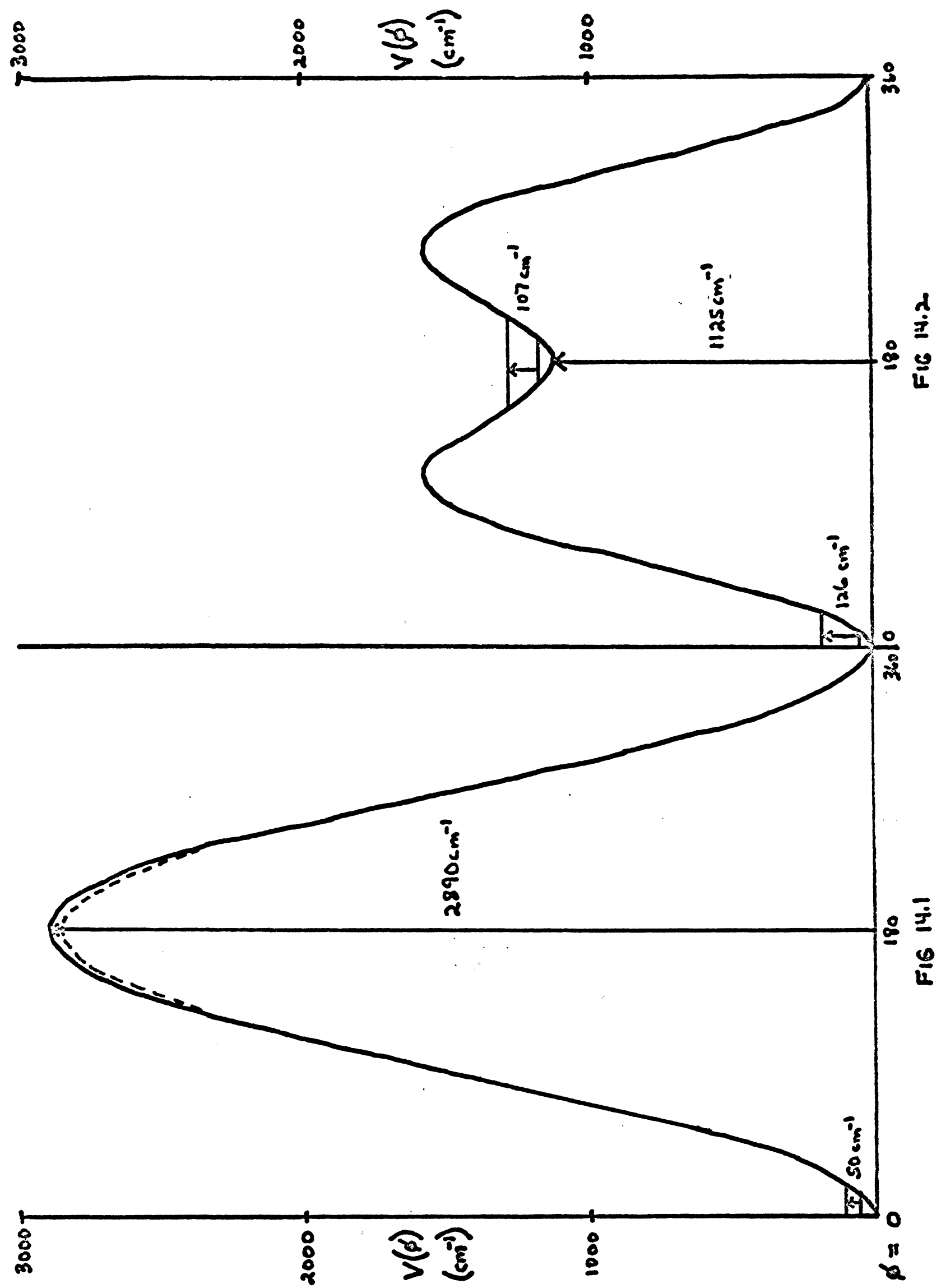


intramolecular torsional potential of 2,3-butanedione with glyoxal as shown in Figure 14.2. Just as steric arguments were used to explain the existence of the cis isomer for glyoxal, steric arguments may also be used to account for 2,3-butanedione existing only in the trans form. As the hydrogen atoms in glyoxal are replaced by the more bulky methyl groups, steric forces would increase between the two methyl groups which results in the trans isomer becoming more stable and sterically favored over the cis form. 


\section{BIBLIOGRAPHY}

1. Currie, G. N. and D. A. Ramsay. "The $4875 \&$ Band System of cis Glyoxal," Canadian Journal of Physics, IL (1971), 317-322.

2. Durig, J. R., C. C. Tong, and Y. S. Li. "Microwave Spectrum of cis-Glyoxal," The Journal of Chemical Physics, LVII (1972), 4425-4427.

3. Durig, J. R., S. E. Hannum, and S. C. Brown. "Vibrational Spectra and Structure of Biacetyl," The Journal of Physical Chemistry, LXXV (1971), 1946-1956.

4. Fately, W. G., R. K. Harris, Foil A. Miller, and R. E. Witkowski. "Torsional Frequencies in the Far Infrared - IV. Torsions Around the C-C Single Bond in Conjugated Molecules," Spectrochimica Acta, XXI (1965), 231-244.

4. Harris, R. K. and R. E. Witkowski. Spectrochimica Acta, XX (1964), 1651 .

5. Hagen, K. and K. Hedberg. "Conformational Analysis. IV. Molecular Structure and Composition of Gaseous 2,3-Butanedione as Determined by Electron Diffraction," Journal American Chemical Society, VC (1973), 82668269.

6. Zahn, C. T. "The Dielectric Constant of Dichlorethane, Dibromethane, Chlorobromethane, and Diacetyl; and the Phenomenon of Free Rotation," Physical Review, XL (1932), 291-298.

7. Bloom, G. I. M. and L. E. Sutton. "Electric Polarization and Molecular Vibrations: The Ethylene Dihalides and Diacetyl," Journal Chemical Society, (1941), 727 .

8. Riddick and Bunger. Organic Solvents. $3 d$ ed. New York: Wiley and Sons, Inc., 1970.

9. Handbook of Chemistry and Physics. 43d ed. Cleveland: The Chemical Rubber Publishing Company, 1961.

10. Jolly and Mayo. Canadian Journal of Chemistry, XLII $(1964), 170$. 
11. Gajjar, Ashvin. "The Dipole Moment of $\mathrm{Cis}$ and Trans Chloroiodoethylene," Master of Science Thesis, Eastern Illinois University, (1970).

12. Cureton, Le Fevre, and Le Fevre. "Molecular Polarisability: The Conformations of Biacetyl, Benzil, and Furil as Solutes in Benzene or Carbon Tetrachloride," Journal Chemical Society, (1961), 4447-4451.

13. Smyth, C. P. Dielectric Behavior and Structure. New York: McGraw-Hill Book Company, Inc., 1955.

14. Shoemaker and Garland. Experiments in Physical Chernistry. 2d ed. New York: McGraw-Hill Book Company, Inc., 1967 .

15. Herzberg, Gerhard. Molecular Spectra and Molecular Structure (II) Infrared and Raman spectra of Polyatomic Molecules. New York: Nostrand Reinhold Company, 1945. 


\section{Appendix 1}

Spectral Data and Vapor Phase Chromatographs 


\begin{tabular}{|c|c|}
\hline INSTRUMENT : & P.E. $154-\mathrm{L}$ \\
\hline COLUMN LENGTH: & $10 \mathrm{ft.}$ \\
\hline SUPPORT : & Solid \\
\hline CARRIER GAS: & Helium \\
\hline FLOW RATE : & $72 \mathrm{ml} / \mathrm{min}$. \\
\hline CHART SPEED: & $1 \mathrm{inch} / \mathrm{min}$. \\
\hline DETECTOR: & $15 \%$ SE -30 \\
\hline PRESSURE : & 10 psig \\
\hline TEMPERA TURES : & $\begin{array}{ll}\text { Column } & 128^{\circ} \mathrm{C} \\
\text { Detector } & 128^{\circ} \mathrm{C}\end{array}$ \\
\hline SENSITIVITY: & 2 \\
\hline SAMPLE SIZE: & $0.2 \mu l, 0.05 \mu l$ \\
\hline
\end{tabular}


75

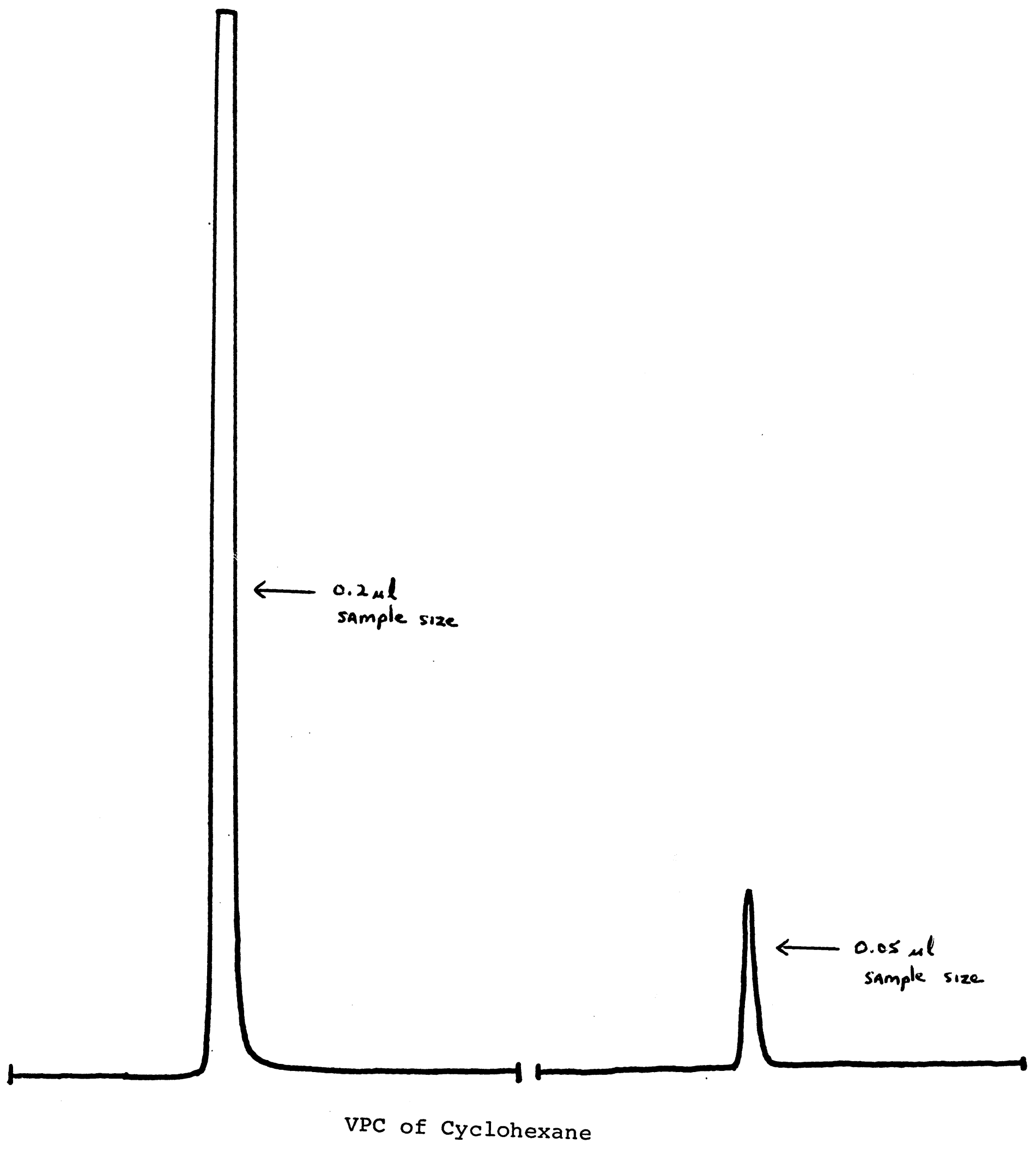




$\begin{aligned} & \text { VPC OF CARBON TETRACHLORIDE } \\ & \text { INSTRUMENT: } \text { P.E. 154-L } \\ & \text { COLUMN LENGTH: } 10 \mathrm{ft} . \\ & \text { SUPPORT: } \text { Solid } \\ & \text { CARRIER GAS : } \text { Helium } \\ & \text { FLOW RATE: } 72 \mathrm{ml} / \mathrm{min} . \\ & \text { CHART SPEED: } 1 \mathrm{inch} / \mathrm{min} . \\ & \text { DETECTOR: } 15 \% \mathrm{sE}-30 \\ & \text { PRESSURE: } 10 \mathrm{psig} \\ & \text { TEMPERATURES : } \text { Column } 96^{\circ} \mathrm{C} \\ & \text { SENSITIVITY: } \text { Detector } 96^{\circ} \mathrm{C} \\ & \text { SAMPLE SIZE: } 2.2 \mu l\end{aligned}$




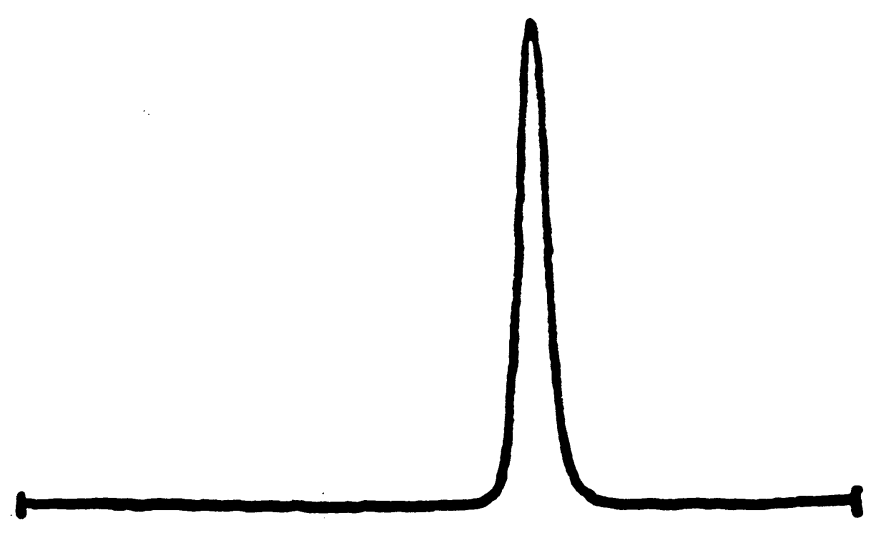

VPC of Carbon Tetrachloride 


$\begin{aligned} & \text { VPC Of BENZENE } \\ & \text { INSTRUMENT : } \text { P.E. 154-L } \\ & \text { COLUMN LENGTH : } 10 \mathrm{ft} . \\ & \text { SUPPORT : } \text { Solid } \\ & \text { CARRIER GAS : } \text { Helium } \\ & \text { FLOW RATE: } 72 \mathrm{ml} / \mathrm{min} . \\ & \text { CHART SPEED : } 1 \mathrm{inch} / \mathrm{min} . \\ & \text { DETECTOR : } 15 \% \mathrm{sE}-30 \\ & \text { PRESSURE : } 10 \mathrm{psig} \\ & \text { TEMPERATURES : } \text { Column } 128^{\circ} \mathrm{C} \\ & \text { Detector } 128^{\circ} \mathrm{C} \\ & \text { SENSITIVITY : } 2 \\ & \text { SAMPLE SIZE: } 0.2 \mu l\end{aligned}$




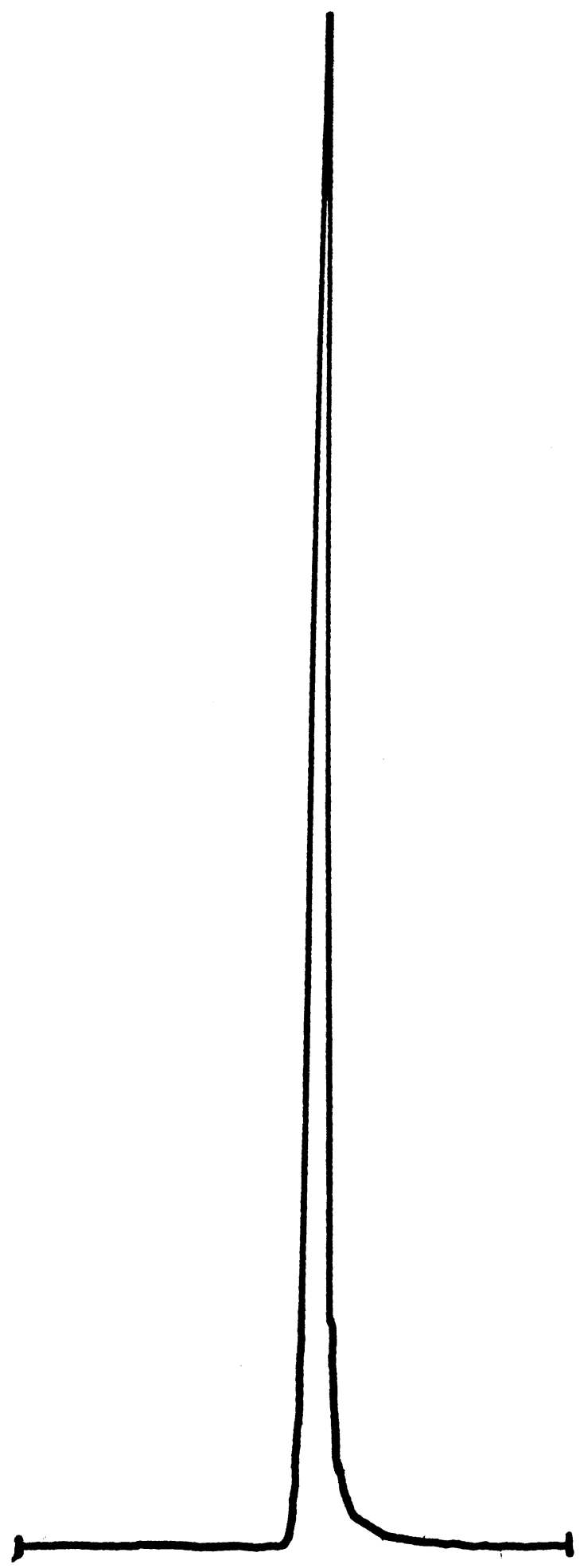

VPC of Benzene 
VPC OF 2,3-BUTANEDIONE

$\begin{aligned} \text { INSTRUMENT: } & \text { P.E. 154-L } \\ \text { COLUMN LENGTH: } & 10 \mathrm{ft.} \\ \text { SUPPORT: } & \text { Solid } \\ \text { CARRIER GAS : } & \text { Helium } \\ \text { FLOW RATE : } & 78 \mathrm{ml} / \mathrm{min} . \\ \text { CHART SPEED: } & 1 \mathrm{inch} / \mathrm{min} . \\ \text { DETECTOR: } & 15 \% \mathrm{sE}-30 \\ \text { PRESSURE: } & 10 \mathrm{psig} \\ \text { TEMPERATURES : } & \text { Column } 114^{\circ} \mathrm{C} \\ \text { SENSITIVITY : } & \text { Detector } 114^{\circ} \mathrm{C} \\ \text { SAMPLE SIZE: } & 8.2 \mu \ell\end{aligned}$




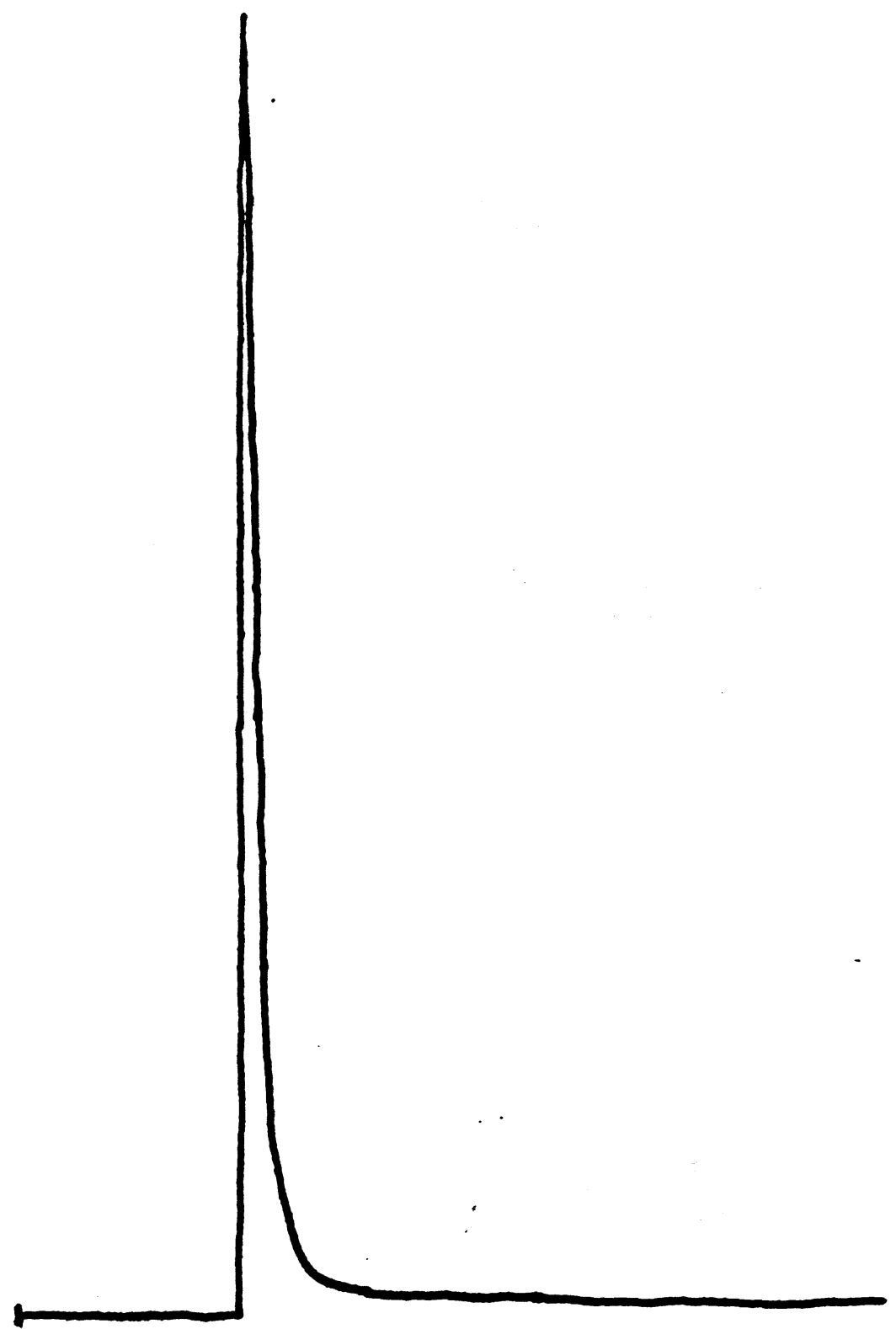

VPC of 2,3-butanedione 
$60 \mathrm{MHz}$ NMR of 2,3-BUTANEDIONE

$\begin{aligned} \text { SWEEP OFFSET: } & \text { OHz } \\ \text { SPECTRUM AMPLITUDE: } & 0.25 \\ \text { SPINNING RATE : } & 42 \mathrm{rPs} \\ \text { SWEEP TIME : } & 250 \mathrm{SeC} \\ \text { SWEEP WIDTH : } & 500 \mathrm{~Hz} \\ \text { FILTER : } & 1.0 \\ \text { RF POWER : } & 0.05\end{aligned}$




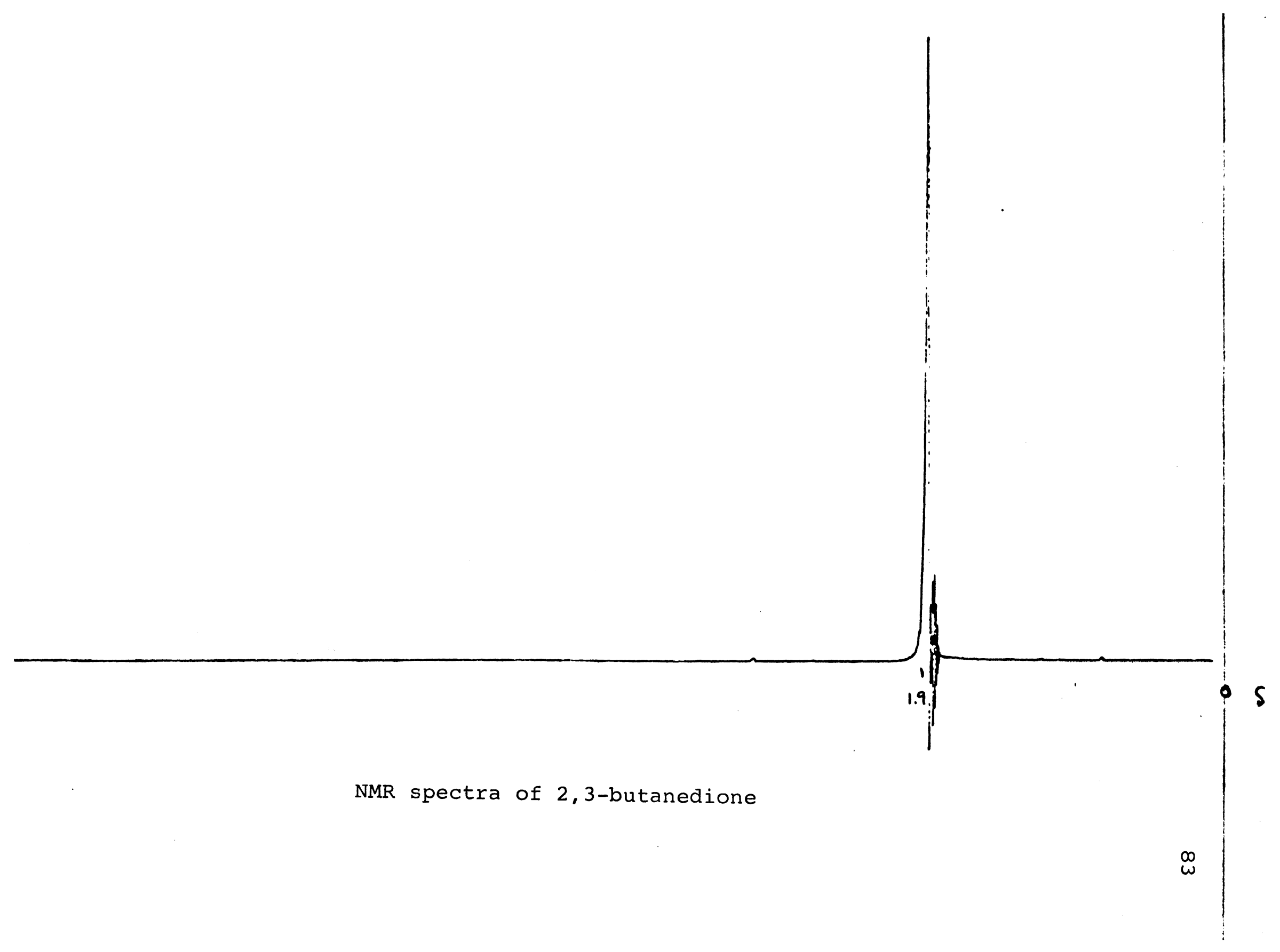


Appendix 2

FORTRAN Computer Programs 
Computer Program Used in Calculating Dipole Moment, Dielectric Constant, Molar Polarization, Distortion Polarization and Orientation Polarization for Pure Liquid Measurements. 


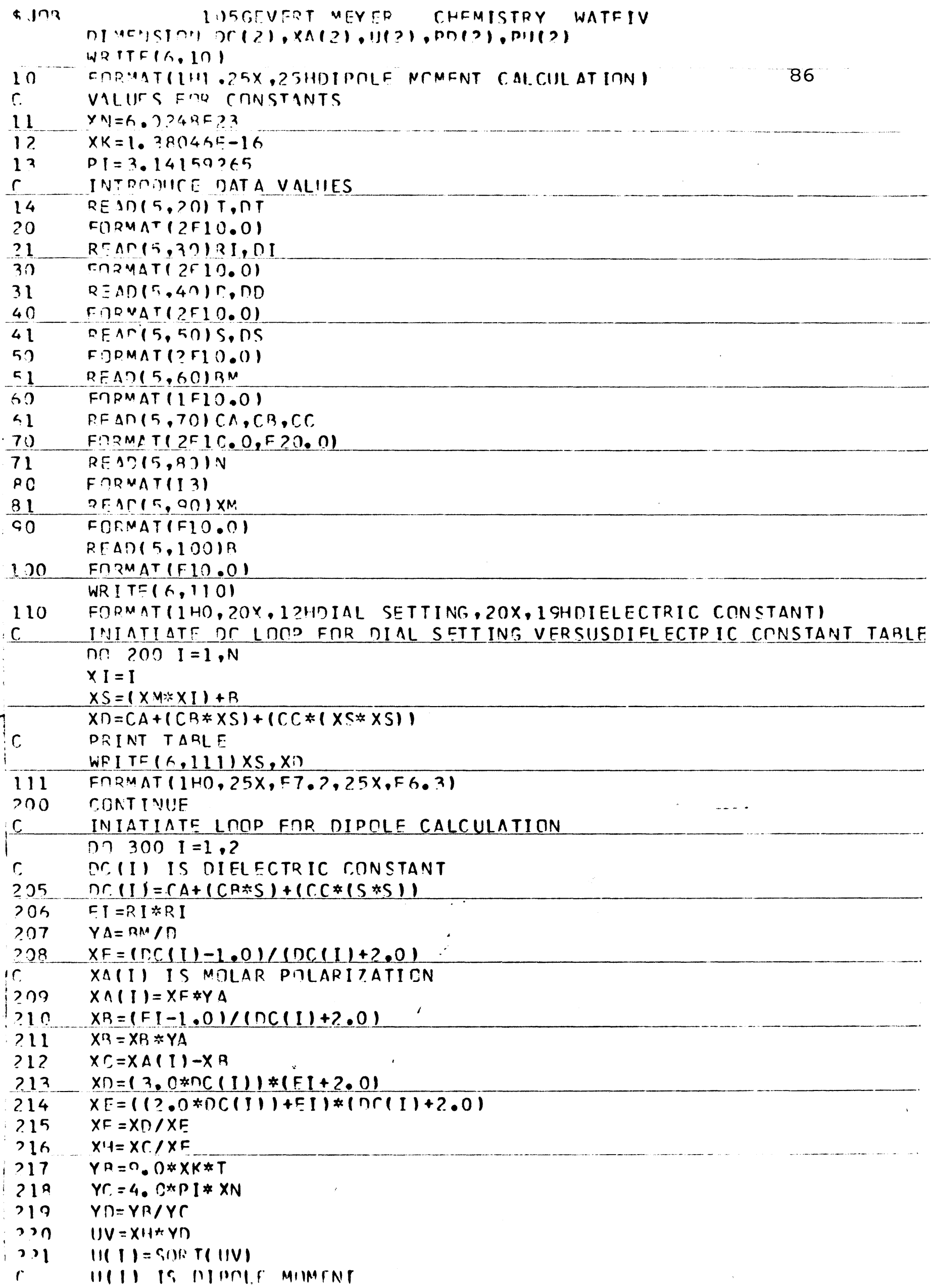




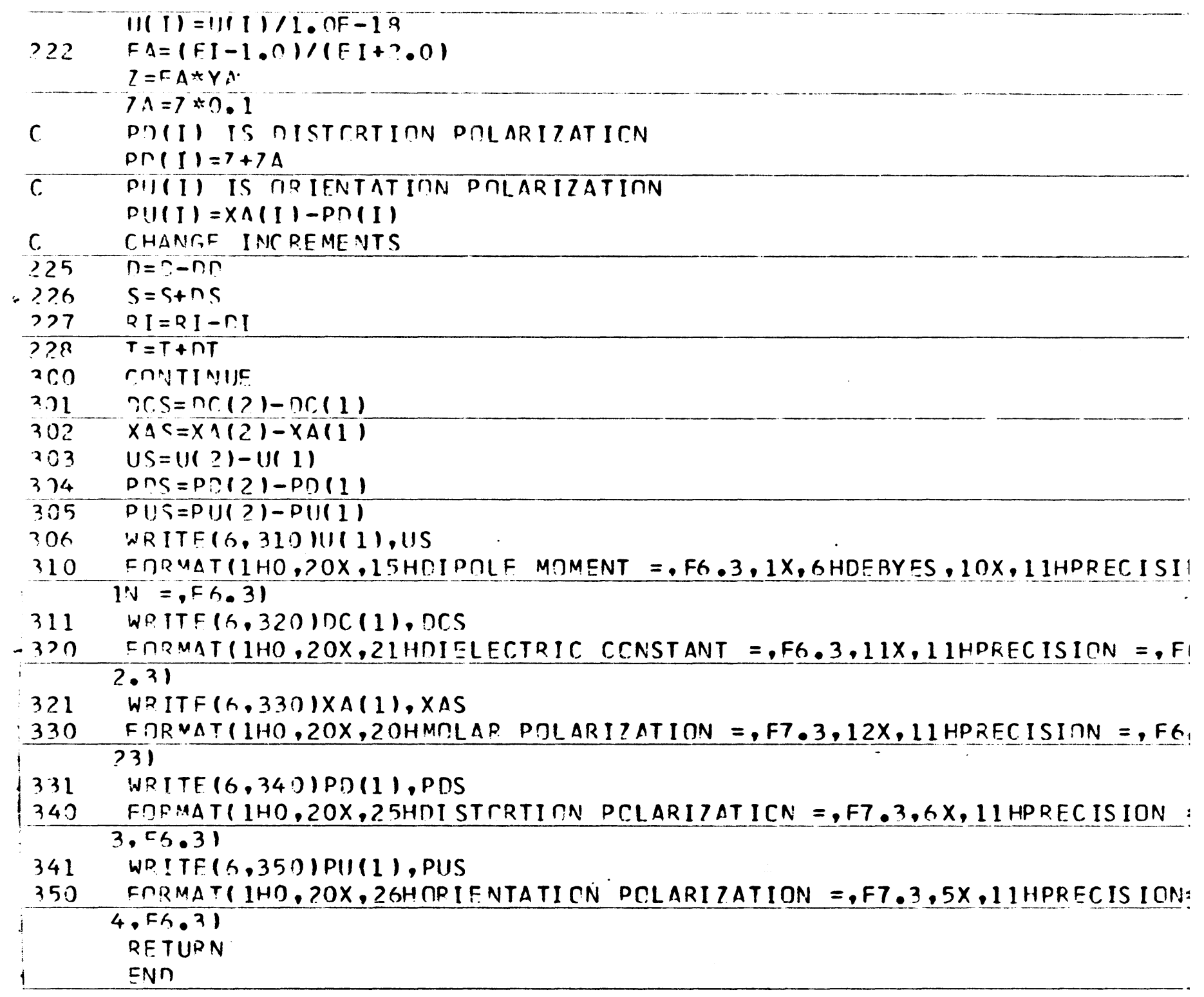


Least Squares Program for Nonlinear Function 


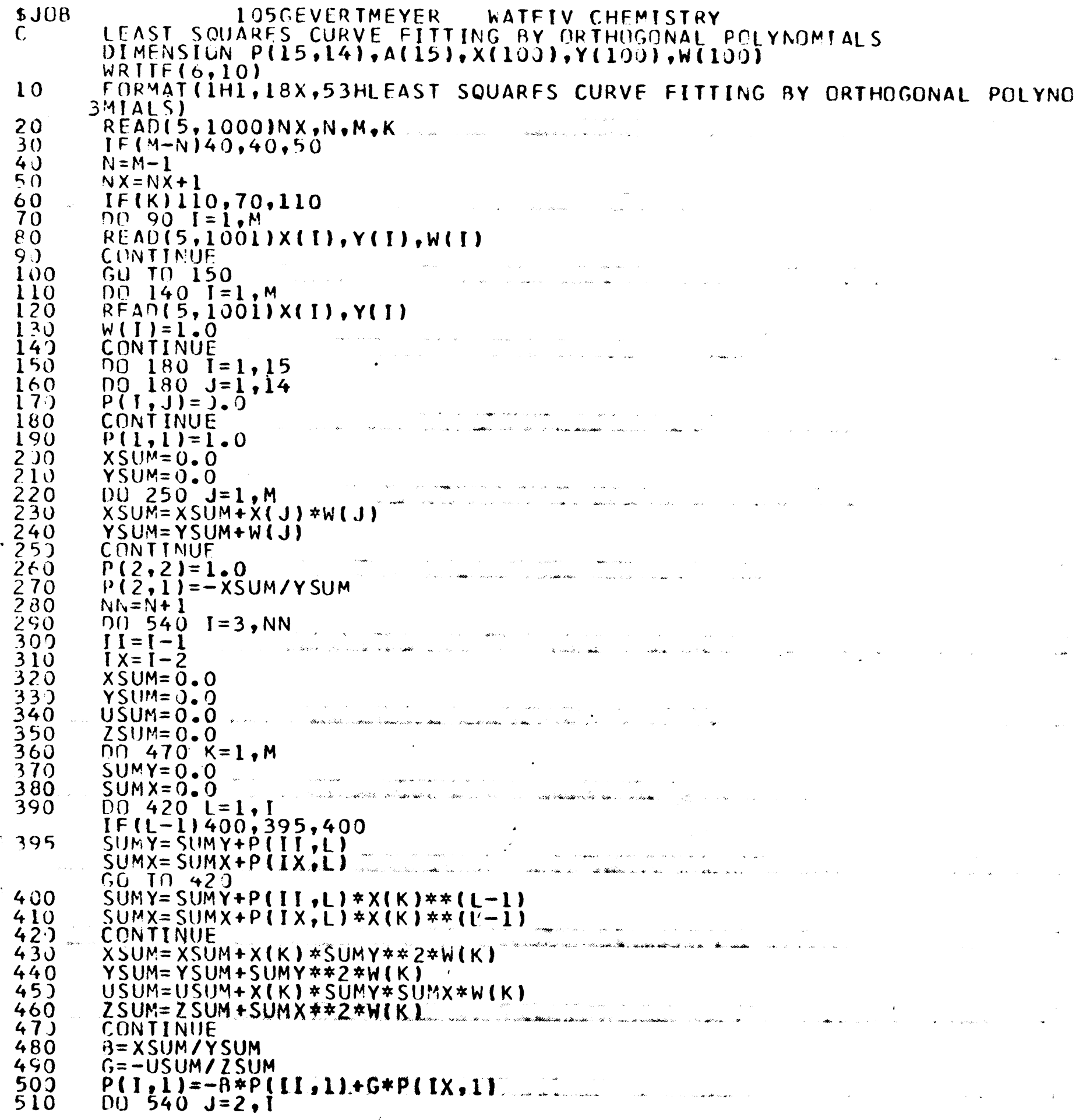




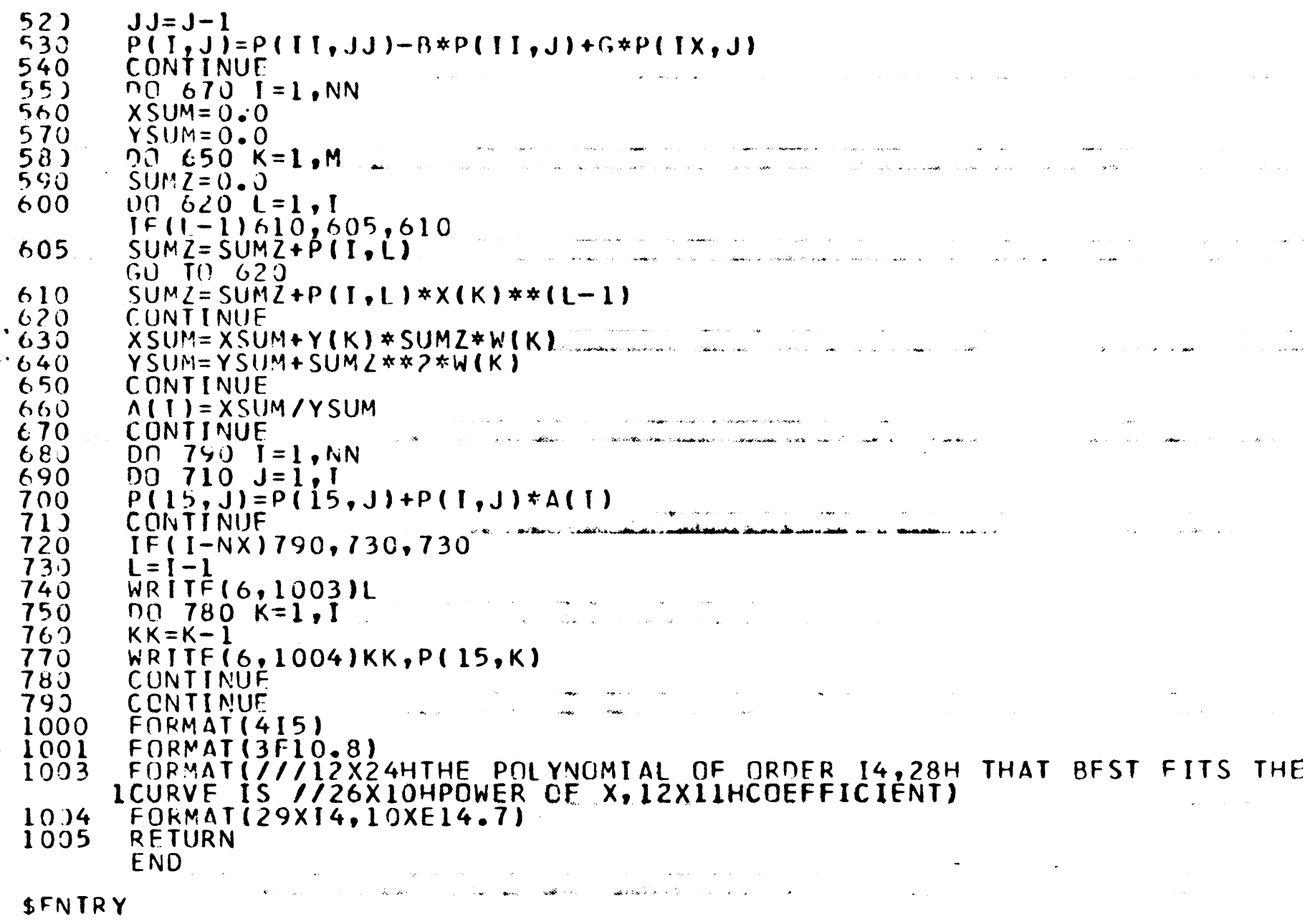


Least Squares Program for Linear Function 


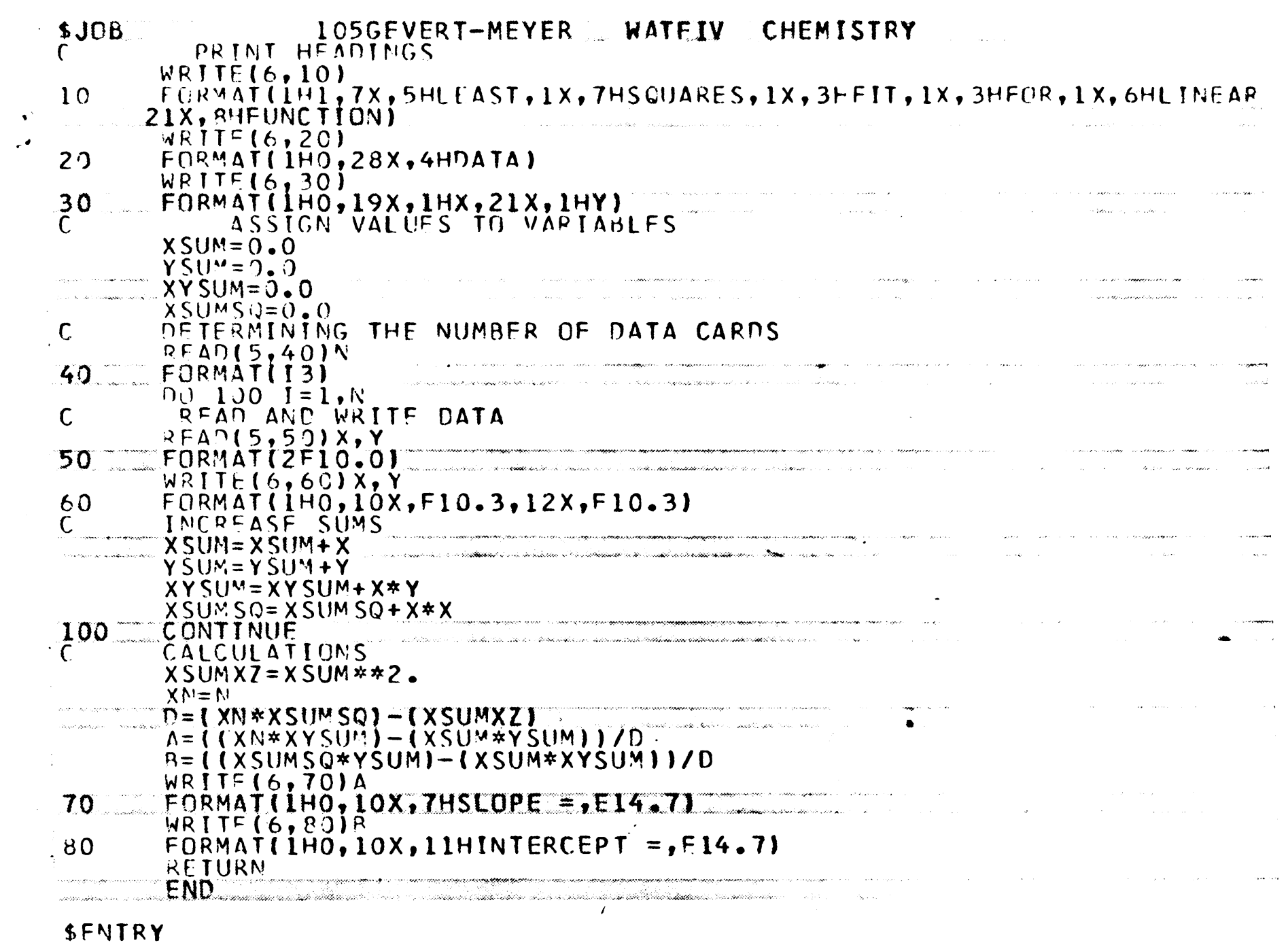


Computer Program Used for Evaluating the Torsional Potential Parameters 


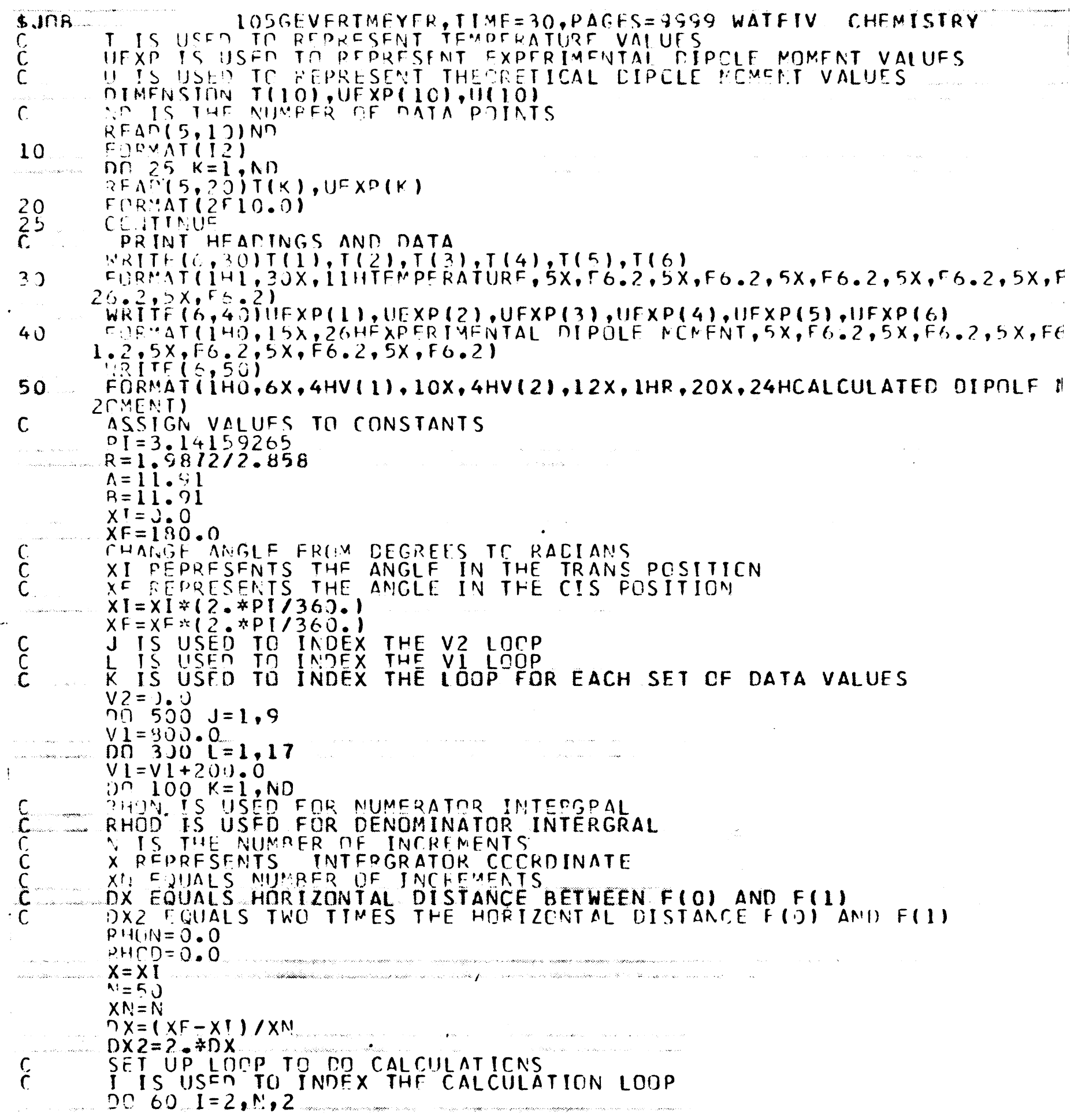




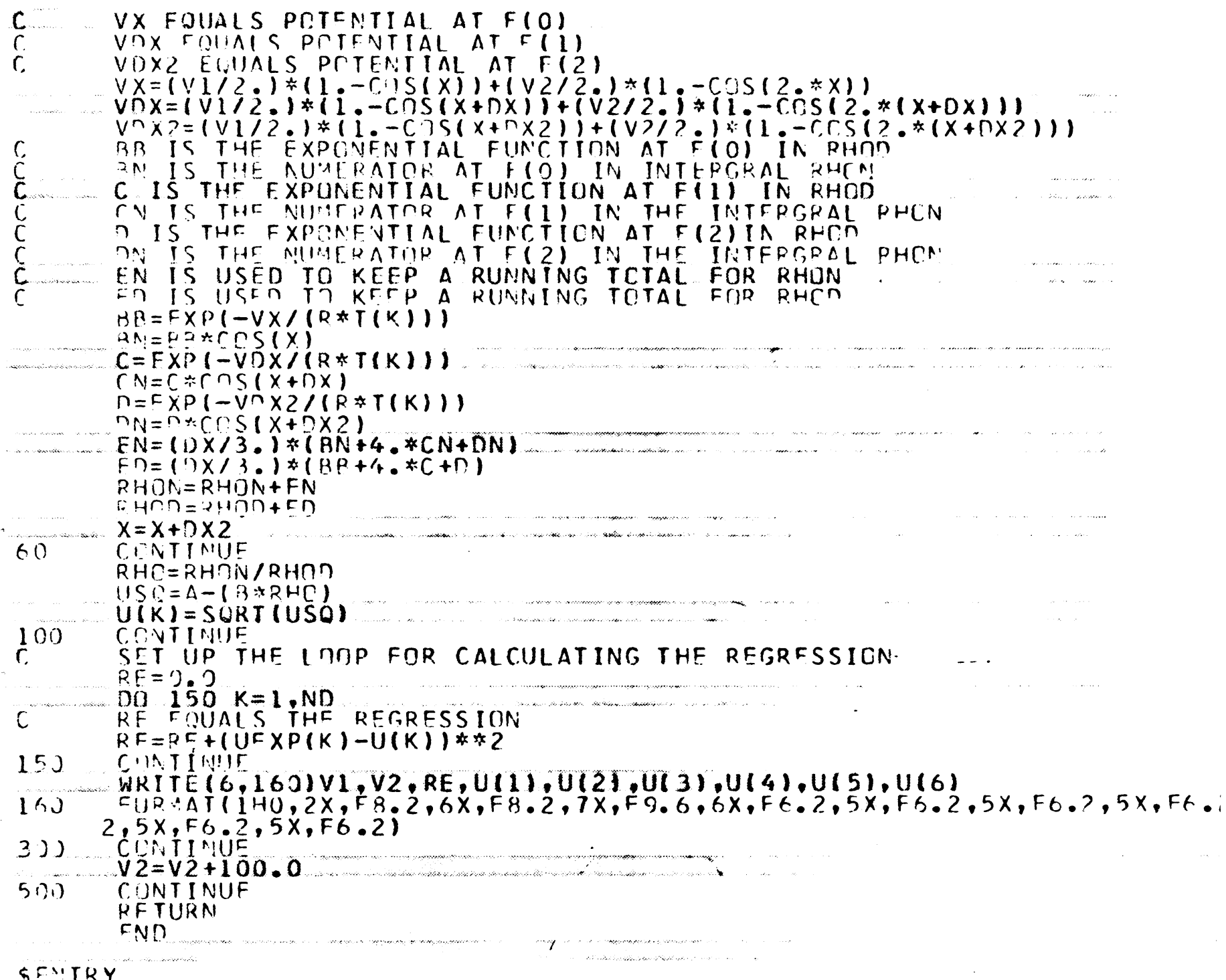




\section{Appendix 3}

Theoretical Relationships of Dielectric Constant, Polarization, and Dipole Moments 


\section{APPENDIX 3}

A molecule will possess an electric dipole when the centers of positive and negative charge do not coincide. This case is represented in the diagram

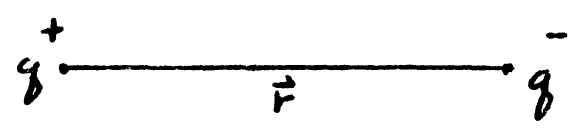

where $\mathrm{q}^{+}$and $\mathrm{q}^{-}$are point charges separated by a vector r. The electric dipole moment is then defined

$$
\vec{\mu}=q \cdot \vec{r}
$$

All molecules placed in an electric field, i.e. between the plates of a charged capacitor, will have an induced dipole moment due to distortion polarization. This type of polarization results when the molecule becomes slightly deformed as the electrons tend to shift their average position closer to the positive plate, leaving the nuclei closer to the negative plate as shown below.

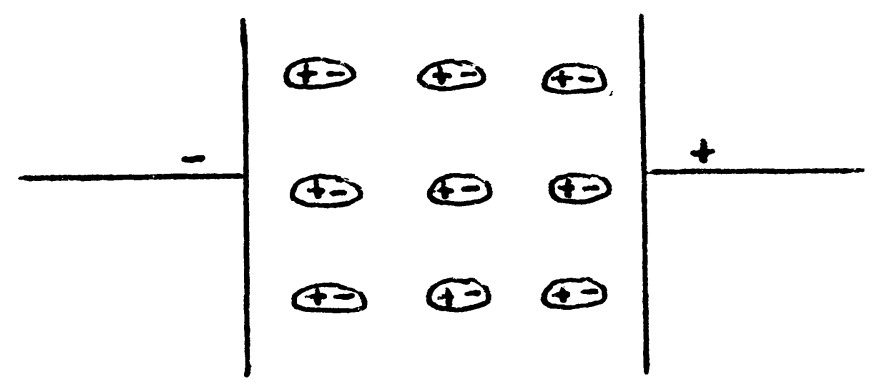


Since the magnitude of this induced dipole depends upon the polarizability of the molecule then the total distortion polarization, $\mathrm{P}_{\mathrm{d}}$, can be given by ${ }^{14}$

$$
P_{d}=\frac{4 \pi}{3} N_{0} \propto
$$

where $\mathrm{N}_{\mathrm{O}}=$ Avagadro's number

$\alpha=$ polarizability of the molecule

In addition to the distortion polarization, polar molecules also have orientation polarization, $\mathrm{P}_{\mathrm{u}}$, due to the presence of a permanent dipole moment. 14

$$
\mathrm{P}_{\mathrm{u}}=\frac{4 \pi}{3} N_{0} \frac{\mu^{2}}{3 h T}
$$

$$
\text { where } \begin{aligned}
\mathrm{k} & =\text { Boltzmann constant } \\
\mathrm{T} & =\text { temperature in } \mathrm{O}_{\mathrm{K}} \\
\mathrm{N}_{\mathrm{O}} & =\text { Avagadro's number } \\
\mathbf{P}_{\mu} & =\text { orientational polarization }
\end{aligned}
$$

In an electric field, polar molecules tend to align with the applied field in so far as allowed by thermal motion. The total molar polarization, $\mathrm{P}_{\mathrm{m}}$, for polar molecules in an applied electric field is then the sum of the distortion polarization and the orientation polarization.

$$
\mathrm{P}_{\mathrm{m}}=\mathrm{P}_{\mathrm{d}}+\mathrm{P}_{\mathrm{u}}
$$

The measurement of the orientation polarization, $\mathrm{P}_{\mathrm{u}}$, 
is of primary importance since the calculation of the dipole moment is dependent upon its solution. However, $\mathrm{P}_{\mathrm{u}}$ cannot be measured directly in the laboratory, but rather must be obtained by taking measurements of the dielectric constant, $\boldsymbol{\epsilon}$.

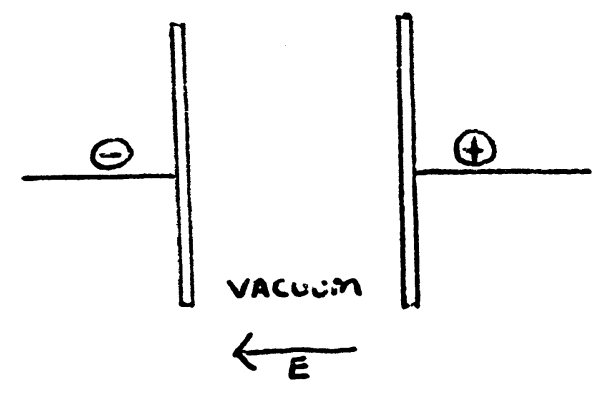

$\mathrm{C}_{\mathrm{O}}=$ Capacitance in vacuum

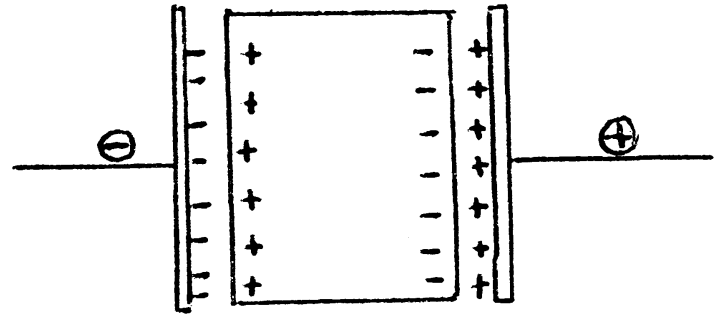

C = Capacitance with dielectric media present

As shown above, when a dielectric media is placed between the plates of a charged capacitor, the dielectric media induces an opposite charge on the plates causing the capacitor to have an additional charge. The dielectric constant is then related to these changes in capacitance where

$$
\epsilon=\frac{c}{c_{0}}>1
$$

Once the dielectric constant has been obtained, then the total molar polarization can be calculated from the Clausius-Mosotti equation. 14

$$
\mathrm{P}_{m}=\frac{\epsilon-1}{\epsilon+2}\left(\frac{m}{p}\right)
$$

where $\mathrm{P}_{\mathrm{m}}=$ molar polarization 


$$
\begin{aligned}
& \epsilon=\text { dielectric constant } \\
& M=\text { molecular weight } \\
& \boldsymbol{\rho}=\text { density }
\end{aligned}
$$

The final quantity needed to solve equation (3) for the orientation polarization is the distortion polarization, $P_{d}$. This can be determined by placing the sample in an electric field that alternates very rapidly and the molecules cannot turn fast enough to keep up with the changing field. As a result, the electrons move much more rapidly and the distortion polarization alone is observed. Thus at optical frequencies the dielectric constant, $\epsilon$, is equal to the index or refraction squared. In the laboratory, distortion polarization is measured by finding the index of refraction. This is given by the relationship presented by Lorentz-Lorenz. 14

$$
\begin{aligned}
& \mathrm{P}_{d}=\frac{m^{2}-1}{m^{2}+2}\left(\frac{m}{\rho}\right) \\
& \text { where } \mathrm{P}_{\mathrm{d}}=\text { distortion polarization } \\
& \mathrm{n}=\text { index of refraction } \\
& M=\text { molecular weight } \\
& \rho=\text { density }
\end{aligned}
$$

Once solution for the molar polarization, $\mathrm{P}_{\mathrm{m}}$, and distortion polarization, $\mathrm{P}_{\mathrm{d}}$, have been obtained, then the dipole moment, $\mu$, can be calculated. Upon rearrangement and the substitution of equation (2) for $P_{u}$, equation (3) then becomes 


$$
\mathrm{P}_{\mathrm{m}}-\mathrm{P}_{\mathrm{d}}=\frac{4 \pi N_{c} \mu^{2}}{9 k T}
$$

Another form for equation (6) is

$$
\frac{\epsilon-1}{\epsilon+2}\left(\frac{m}{p}\right)-\frac{m^{2}-1}{m^{2}+2}\left(\frac{m}{p}\right)=\frac{4 \pi N \mu^{2}}{9 k T}
$$

$$
\begin{aligned}
\text { where } \boldsymbol{\epsilon} & =\text { dielectric constant } \\
\mathrm{M} & =\text { molecular weight } \\
\boldsymbol{P} & =\text { density } \\
\mathrm{n} & =\text { index of refraction } \\
\mathrm{N} & =\text { Avagadro's number } \\
\mathrm{K} & =\text { Boltzmann constant } \\
\mathrm{T} & =\text { temperature in } \mathrm{O}_{\mathrm{K}} \\
\boldsymbol{\mu} & =\text { dipole moment }
\end{aligned}
$$

which is known as the Debye equation. ${ }^{13}$ The Debye equation is used to calculate dipole moment for gases at or below atmospheric pressure. When dipole moment measurements are carried out on pure polar liquids, the Debye equation is modified in the following manner. 13

$\frac{E-1}{\epsilon+2}\left(\frac{m}{p}\right)-\frac{m^{2}-1}{m^{2}+2}\left(\frac{m}{p}\right)=\frac{3 \epsilon(n+2)}{(2 \epsilon+m)(\epsilon+2)} \frac{4 \pi N \mu^{2}}{9 k T}$

which is known as the Onsager equation. The Onsager equation differs from the Debye equation by the factor

$$
\frac{3 \epsilon(n+2)}{(2 \epsilon+n)(\epsilon+2)}
$$

This is due in part to the dipole moment in pure liquids being affected by the interaction of adjacent molecules. 
In solutions, a polar solute molecule is surrounded by non-polar solvent thereby eliminating dipole-dipole (solute-solute) interactions which occur in pure liquids. The subscripts (1), (2), and $(1,2)$ used in the upcoming equations have the meaning given below

(1) = non polar solvent

(2) $=$ polar solute

$(1,2)=$ solution properties

In dilute solutions where a polar solute is surrounded by non-polar solvent molecules, the total molar polarization can be written 14

$$
P_{m}=\bar{x}_{1} P_{1 m}+\bar{x}_{2} P_{2 m}=\frac{\epsilon_{12}-1}{\epsilon_{12}+2} \frac{\left(\bar{x}_{1} m_{1}+\bar{x}_{2} m_{2}\right)}{p}
$$

Since the solvent is non-polar and has only distortion polarization, the molar polarization for the solvent is the same as found in the pure solvent, that is

$$
P_{1 m}=\frac{\epsilon_{1}-1}{\epsilon_{1}+2}\left(\frac{m_{1}}{p_{1}}\right)
$$

The $\mathrm{P}_{2 \mathrm{~m}}$ term, which contains the dipole moment, can be solved upon rearrangement of equation (9)

$$
P_{2 m}=\frac{1}{\bar{x}_{2}}\left(P_{m}-P_{1 m} \bar{x}_{1}\right)
$$

In the laboratory, this quantity can be obtained by a method known as the Hedestrand method. ${ }^{14}$ For this case, 
the assumption is made that a linear dependence exists between $\epsilon$ and $p$ on mole fraction $\bar{x}_{2}$.

$$
\begin{aligned}
& \epsilon=\epsilon_{1}+a \bar{x}_{2} \\
& \rho=p_{1}+b \bar{x}_{2}
\end{aligned}
$$

Equations (9), (10), (11), and (12) all can be combined and rearranged to form the Hedestrand equation, which solves for the molar polarization of the pure solute.

$$
P_{2 m}^{0}=\frac{3 m_{1} a}{\left(\epsilon_{1}+2\right)^{2} p_{1}}+\frac{\epsilon_{1}-1}{\left(\epsilon_{1}+2\right) p_{1}}\left(m_{2}-\frac{m_{1} b}{p_{1}}\right)
$$

After making the assumption that the molar distortion polarization, at infinite dilution, is equal to the molar refractivity of pure solute, ${ }^{a}$ the following equation can be written.

$$
P_{2 d}^{c}=R_{2 m}=\frac{n_{2}^{2}-1}{n_{2}^{2}+2}\left(\frac{m_{2}}{P_{2}}\right)
$$

The orientational polarization of the pure solute can now be solved for in terms of the total molar polarization and distortion polarization.

$$
P_{2 \mu}^{0}=R_{2 m}-P_{2 d}^{0}=\frac{4 \pi N_{0} \mu^{2}}{9 k T}
$$

Equation (16) allows for the dipole moment of the pure solute in solution to be solved for.

$$
{ }^{\mathrm{a}} \mathrm{P}_{2 \mathrm{~d}}=\mathrm{R}_{2 \mathrm{~m}} \times 1.1
$$


Appendix 4

Bond Moments and Molecular Dipole Moment 


\section{APPENDIX 4}

The values for $A$ and $B$ in equation (6) were calculated as follows: The dipole moment for the carbonyl group was averaged from three different sources.

(1) Acetone ${ }^{1}$

$$
\vec{\mu}_{\mathrm{CO}}=2.86 \mathrm{D}
$$

(2) Camphorquinone ${ }^{2}$

$$
\vec{\mu}_{\text {ce }}=2.72 \mathrm{D}
$$

(3) Cis-glyoxal ${ }^{3}$

$$
\begin{aligned}
\vec{u} & =4.8 \pm .2 \mathrm{D} \\
\angle \mathrm{CCO} & =123.9^{\circ}
\end{aligned}
$$

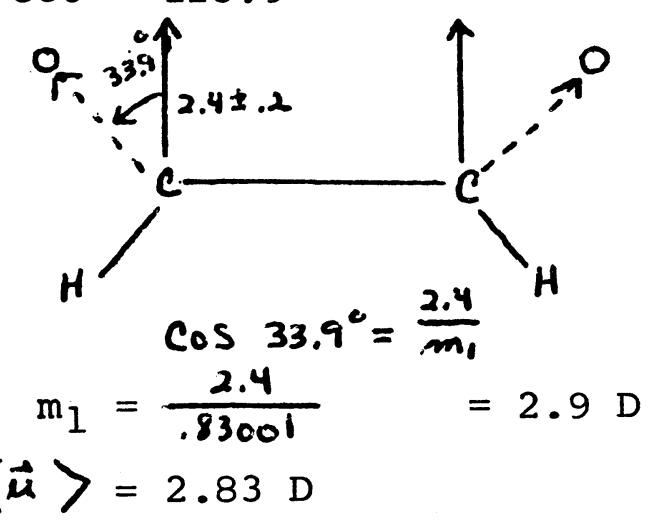

$1_{\text {A. L. McClellan, Table of Experimental Dipole }}$

Moments (San Francisco: W. H. Freeman and Co., 1963).

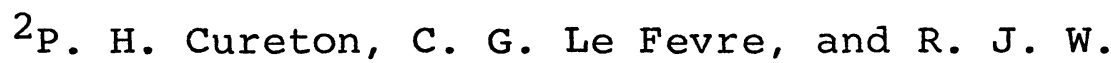
Le Fevre, "Molecular Polarisability: The Conformations of Biacetyl, Benzil, and Furil as Solutes in Benzene or Carbon Tetrachloride," Journal of Chemical Society, (1961), 44474451 .

$3^{J}$. R. Durig, C. C. Tong, and Y. S. Li, "Microwave Spectrum of cis-Glyoxal," The Journal of Chemical Physics, LVII (1972), 4425-4427. 
The average dipole moment for the carbonyl

functional group was then used in conjunction with the structure of gaseous 2,3-butanedione as determined by electron diffraction. 4

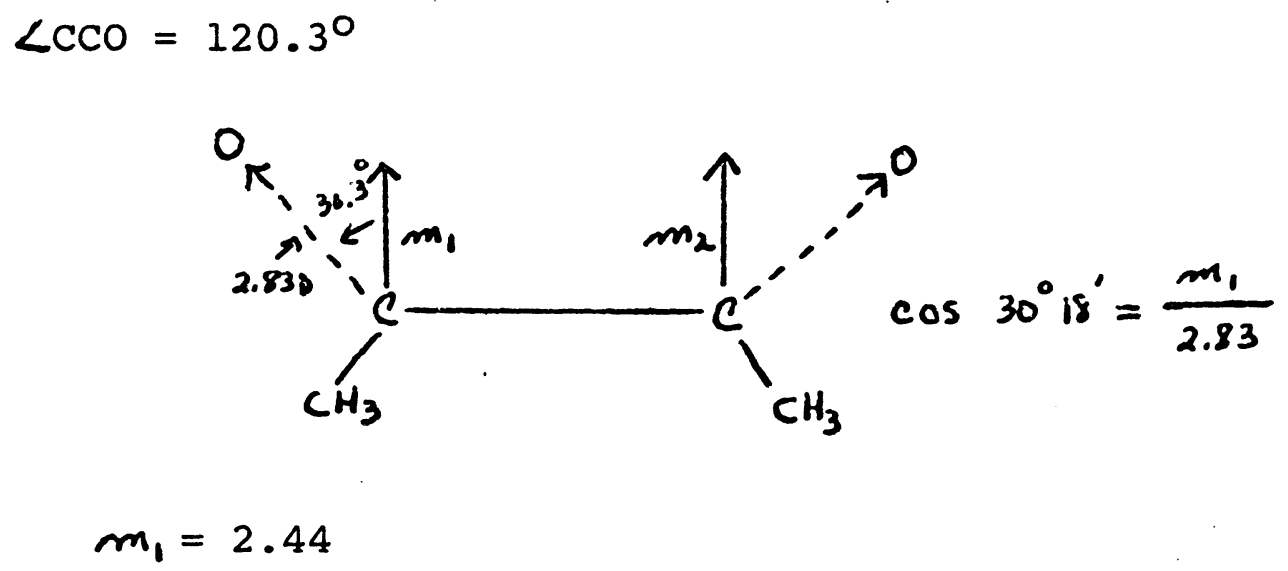

The values for $A$ and $B$ can then be calculated

where

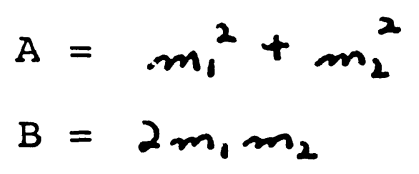

For 2,3-butanedione

$$
\begin{aligned}
A=B & =2 m_{1} m_{2} \\
& =2(2.44) \quad(2.44) \\
A=B & =11.91 \mathrm{D}^{2}
\end{aligned}
$$

${ }^{4} \mathrm{~K}$. Hagen and $\mathrm{K}$. Hedberg, "Conformational Analysis, IV. Molecular Structure and Composition of Gaseous 2,3Butanedione as Determined by Electron Diffraction," Journal American Chemical Society, VC (1973), 8266-8269. 